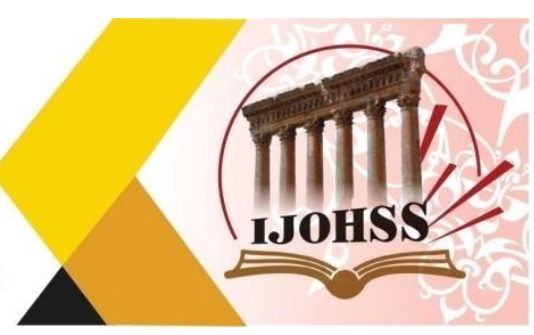

\title{
الامن في القران الكريم وأثرة على حياة الناس (دراسة بيانية)
}

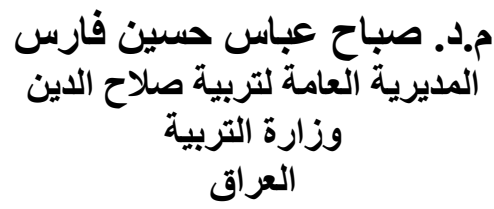

م.د. محمد محمود حسين فارس المد المديرية العامة لتربية صلاح الدين فارين وزارة التربية العراق

الملخص - - ال

إن مـن أكبر النعم التي انعمها الله تعلى على الانسان بعد الاسـلام هي نعمة الامـن و الاطمئنان، وهما مرتبطتان

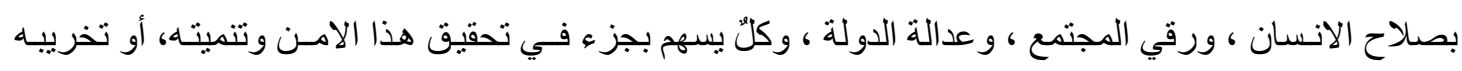
وتدميره. و الامسن في الاسـلام فريضة شر عية، وضرورة حياتية ، لا يستغنى عنها إنسان ولا حيوان و لا طير و ولا جمـاد

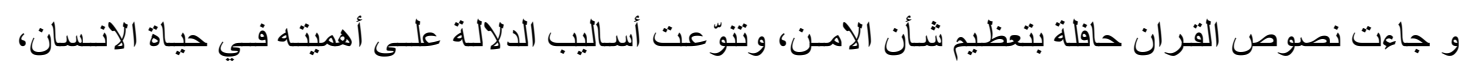
و مـن ذلك امتنانه تعالى على المسلمين بنعمة الامـن في البلد الحرام. الكلمات المفتاحية: الامـن، القران الكريم، الناس، الطمأنينة، الامـن الاجتماعي. 


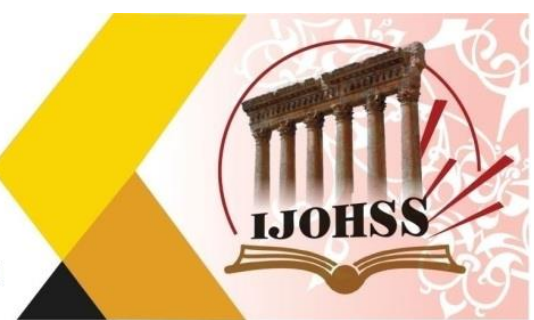

\title{
Security in the Holy Quran and its Impact on People's Lives (A graphic study)
}

\author{
Dr. Mohamed Mahmoud Hussein Fares \\ General Directorate of Education, Salah al- \\ Din \\ Ministry of Education \\ Iraq
}

\author{
Dr. Sabah Abbas Hussein Fares \\ General Directorate of Education, \\ Salah al-Din \\ Ministry of Education \\ Iraq
}

\begin{abstract}
One of the greatest blessings that Allah has bestowed upon man after Islam is the blessing of security and tranquility, and they are linked to the goodness of man, the advancement of society, and the justice of the state, and each part contributes to the realization and development of this security, or its sabotage and destruction.

Security in Islam is a legal obligation, and a life necessity, which no person, animal, bird or inanimate can dispense with. The texts of the Qur'an are full of glorifying the importance of security, and the methods of demonstrating its importance in human life varied, including his gratitude to Muslims for the blessing of security in the Sacred Land.
\end{abstract}

Keywords: security, the Noble Qur'an, people, tranquility, social security. 


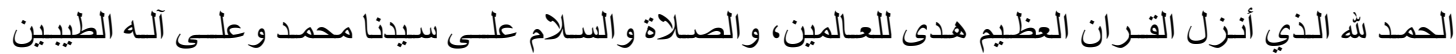
الطاهرين، و أصحابه الغر المبامين. أما بعد.....

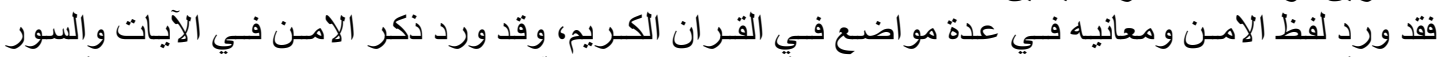

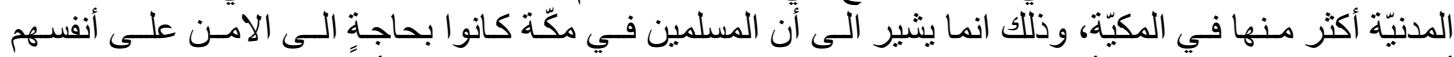

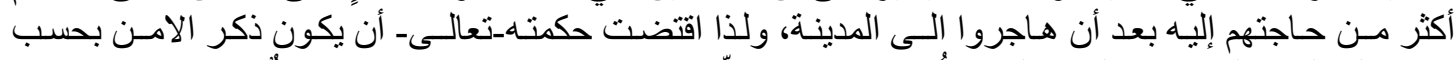

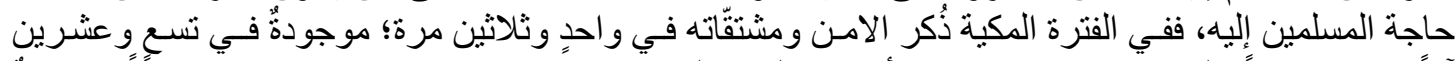

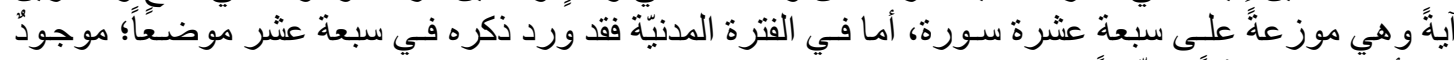

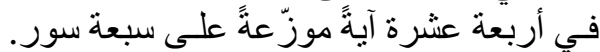

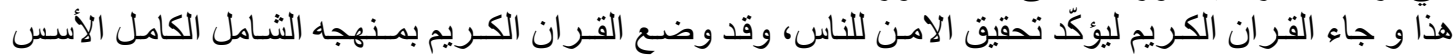

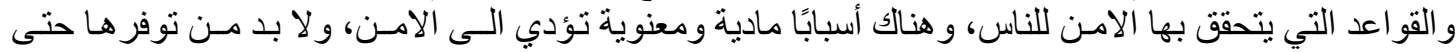

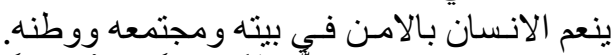

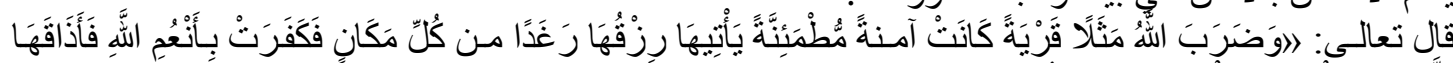

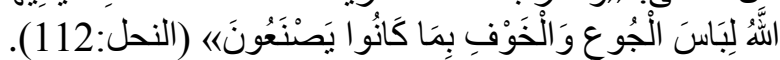

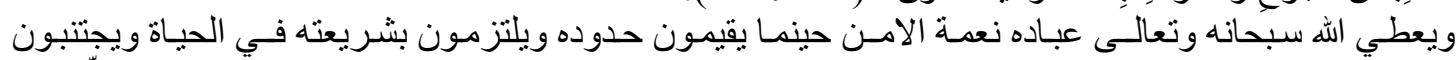

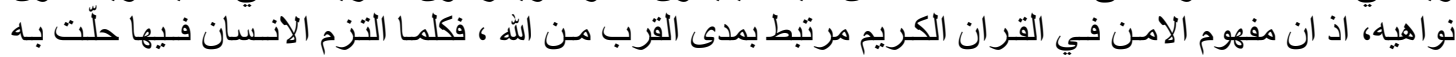

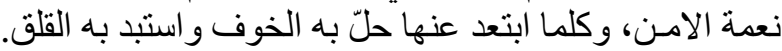

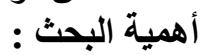

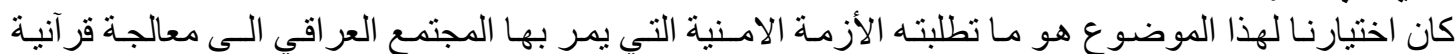

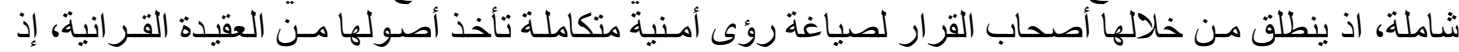

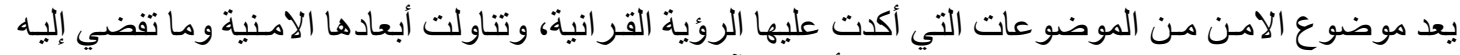

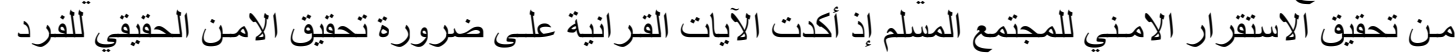

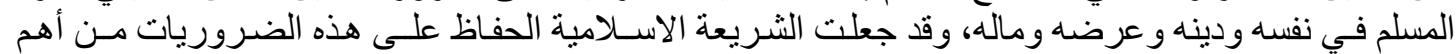

مقاصدها.

\section{التمهيد \\ مفهوم الامسن في اللغة والاصطلاح}

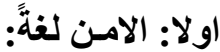

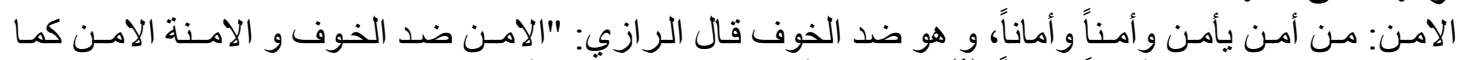

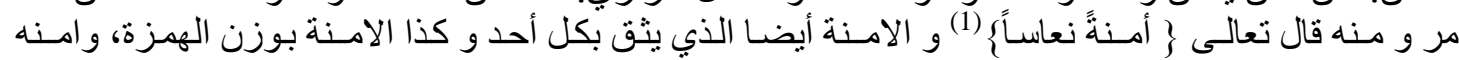

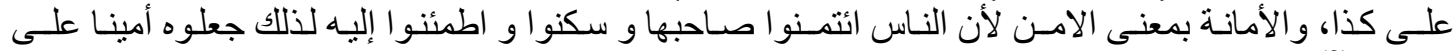

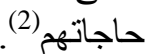

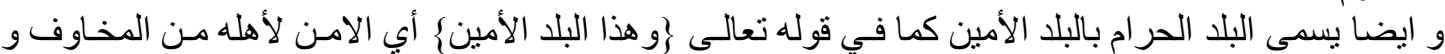

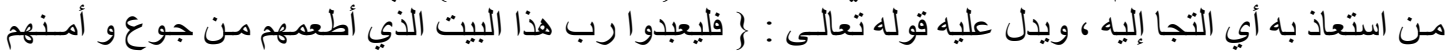

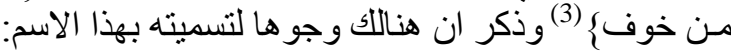
أحدها : أن الله تعالى حفظه عن ان الفيل. وثثانيها : أنها تحفظ للك جميع الأشياء فمباح الدم عند الالتجاء إليها امسن مسن السباع و الصيود تستف يد مـنها الحفظ عند الالتجاء إليهان(4). و الامـن مصدر امـن، وفعلها مـن باب فهم ، وسلم (5) ؛ و والأمسان و الأمانـة بمعنى، وقد امـنت فأنـا امـن، و أمـنت

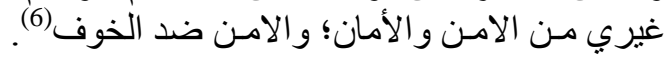




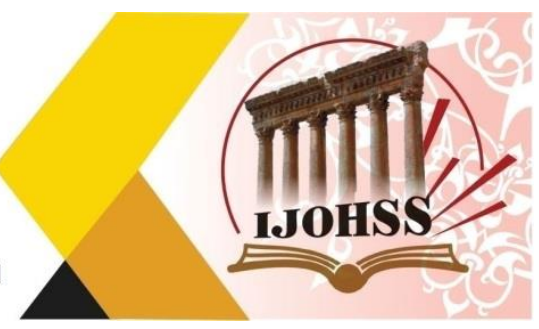

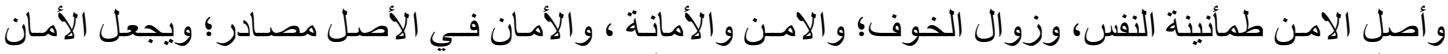

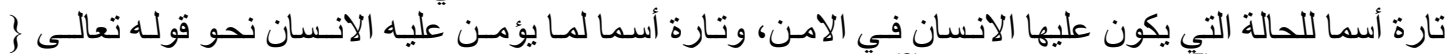

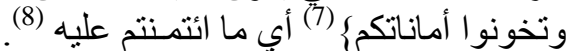

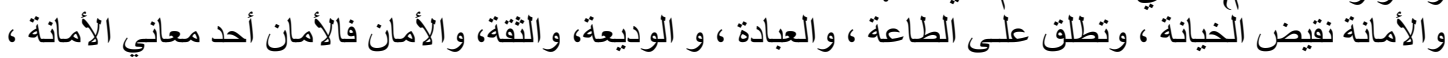

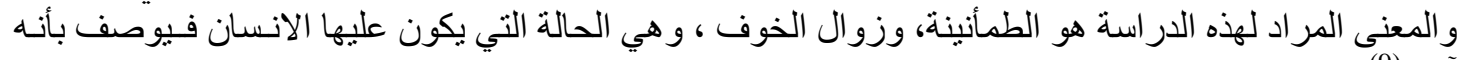

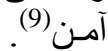

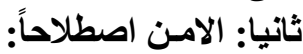

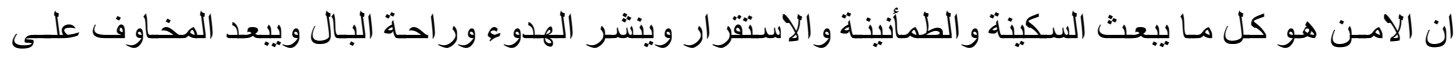

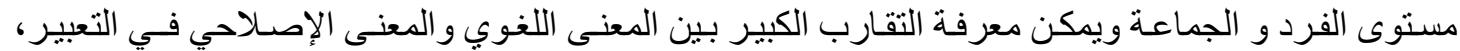

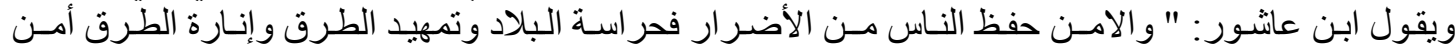

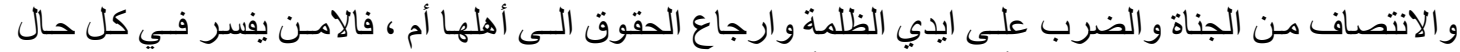

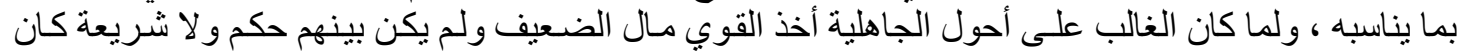

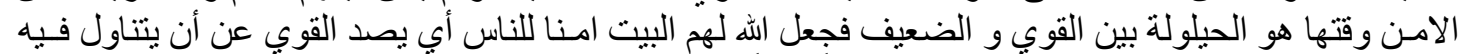

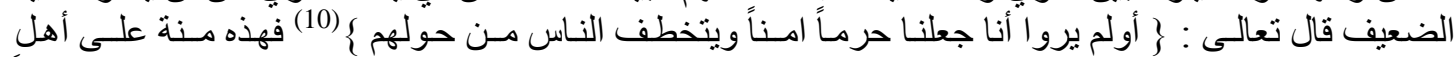

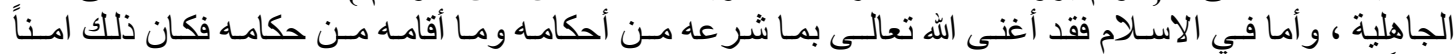

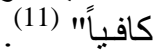

وقال الجرجاني: "ان الامسن هو عدم توقع مكروه في الزمان النّان الآتي (12)".

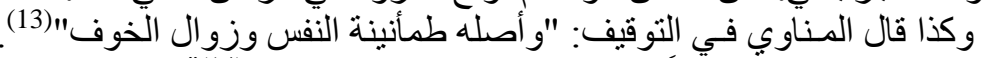

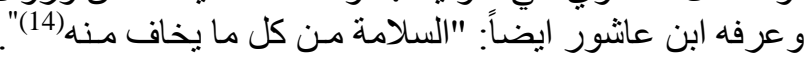

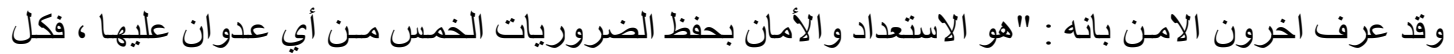

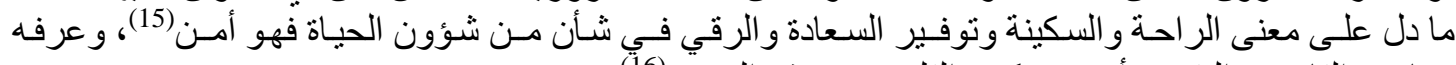

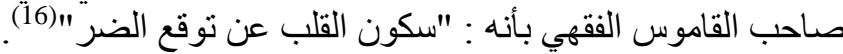

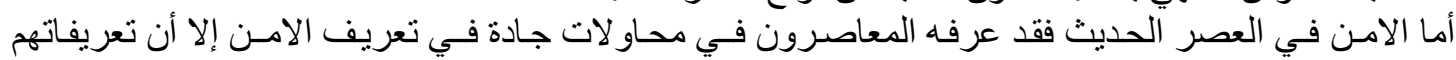

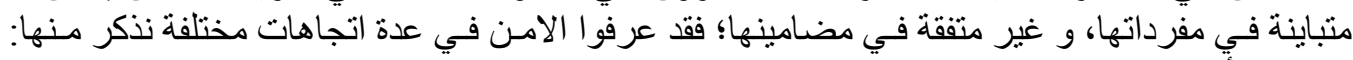

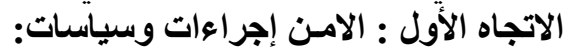

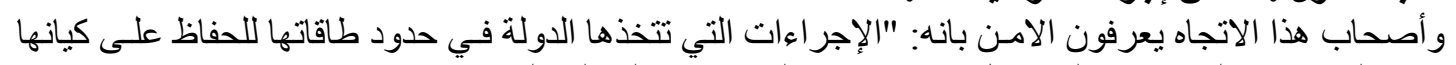

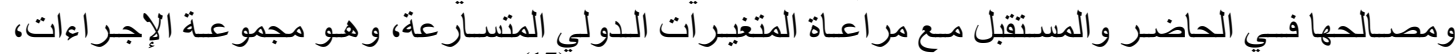

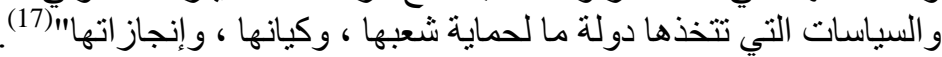
الاتجاه الثاني : الامسن شعور وإحساس:

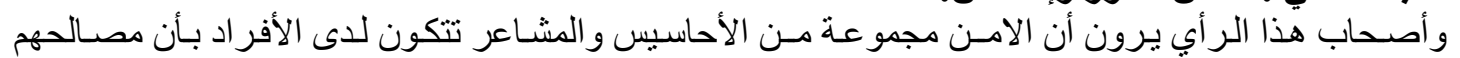

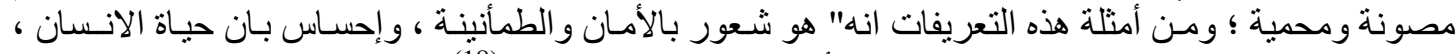

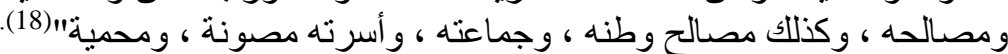

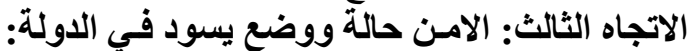

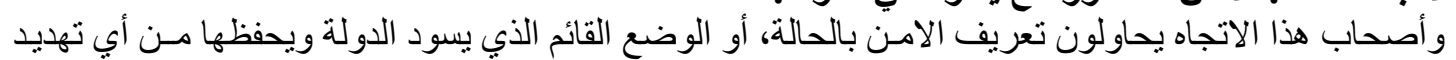

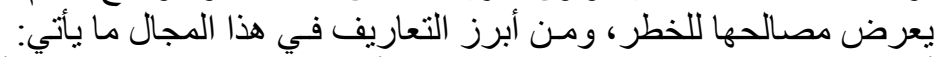

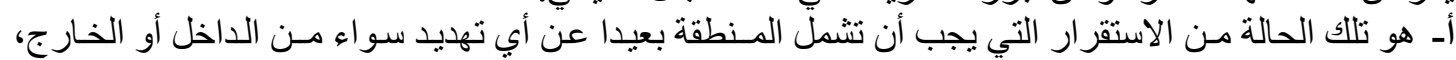

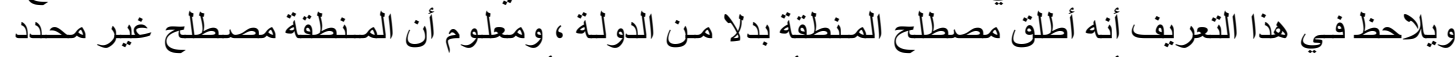

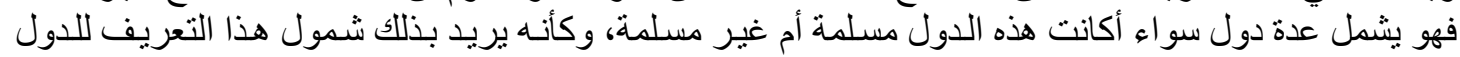

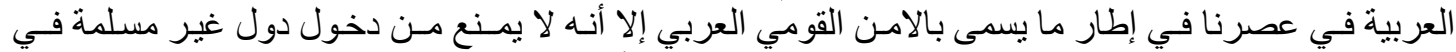

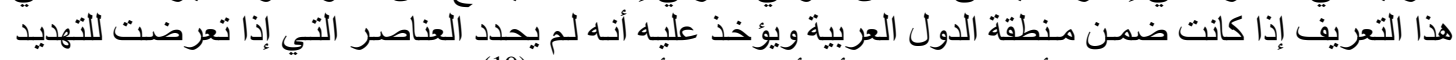

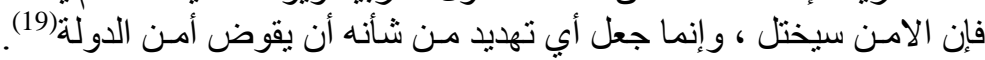

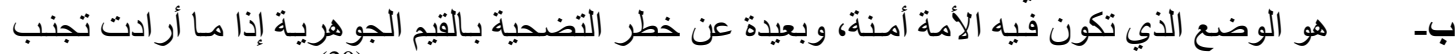
الحرب ، وتكون قادرة على إدامة تلك القيم عن طريق إحر از النصر النصر و المحافظة عليه(20). 


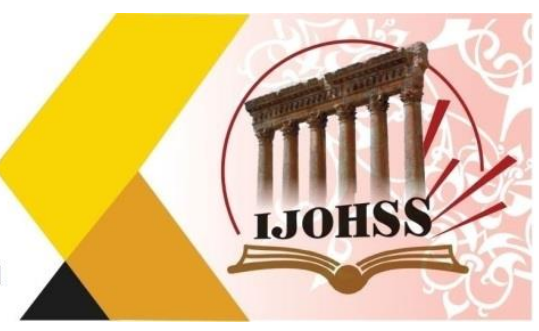

\section{المبحث الاول \\ انواع الامن وتحقيقه للمؤمنين في القران الكريم}

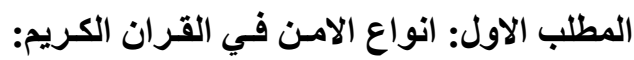

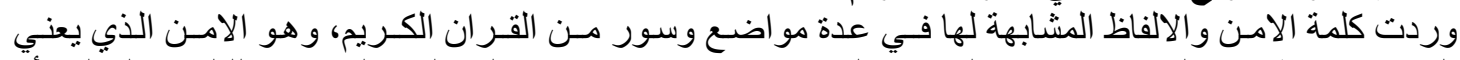

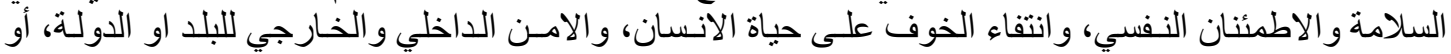

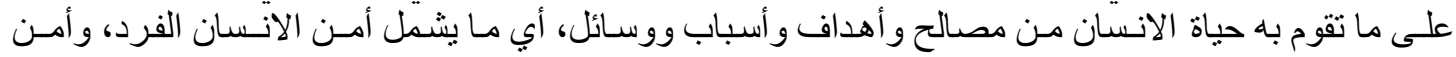

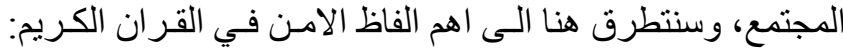
اولا: الامسن النفسي للإنسان:

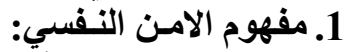

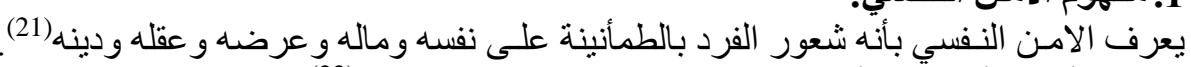

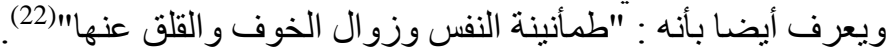

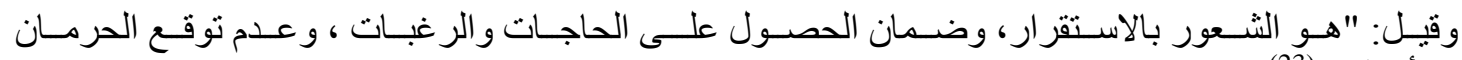
و والأخطار "ه(23). وقيل: "هو شعور المر ع بقيمته الشخصية واطمئنانه السى وضعه وثقته بنفسه"(24).

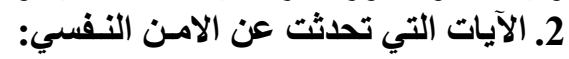

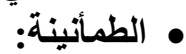

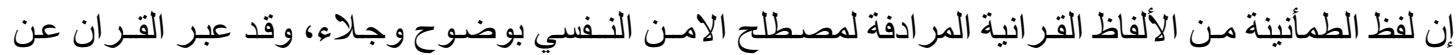

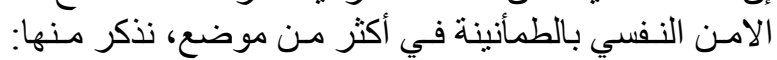

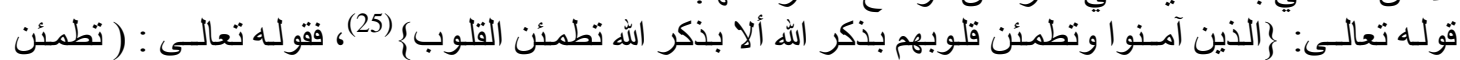

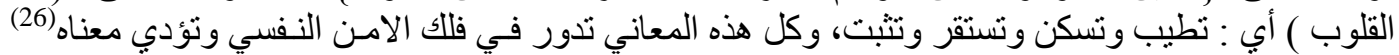

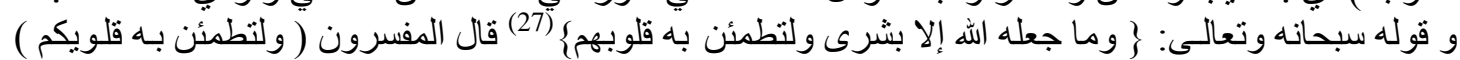

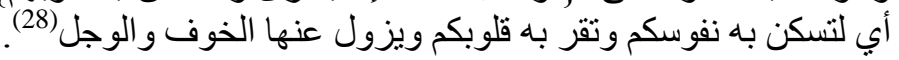

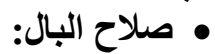
و البال مـن معاني النفس اللغوية، ومـن أسماء النفس : البال، و البال أيضـا : الفكر و القلب و العقل، قال البال العسكري:

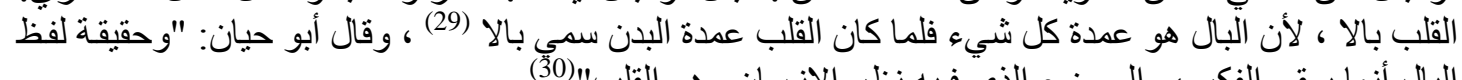

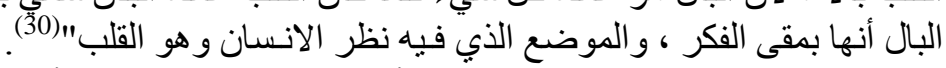

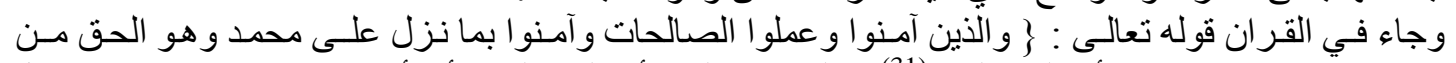

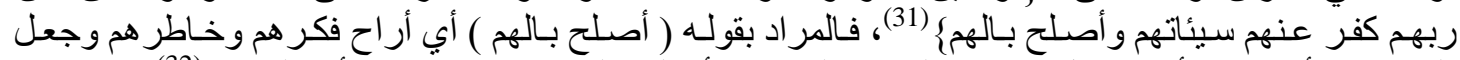

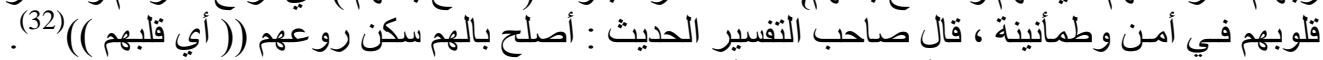

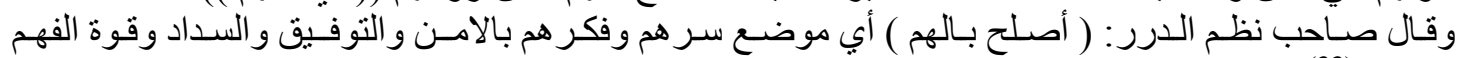
و الرشاد (33).

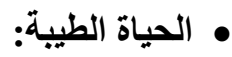

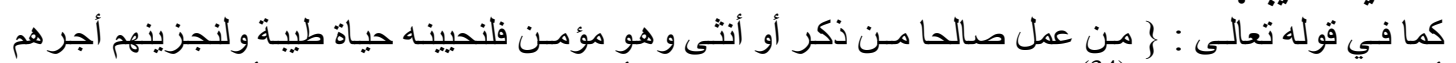

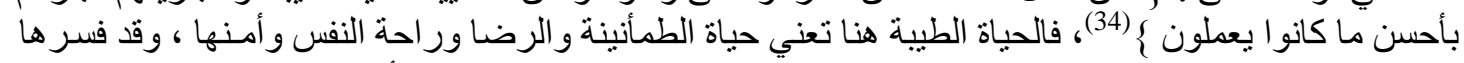

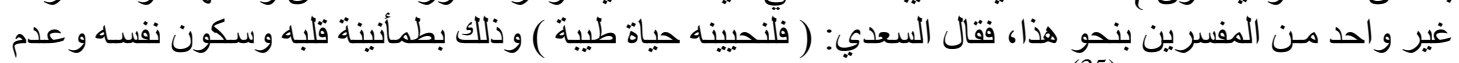
التفاته لما يشوش عليه قلبه (35)

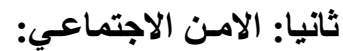

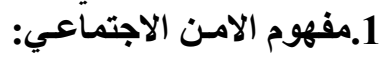

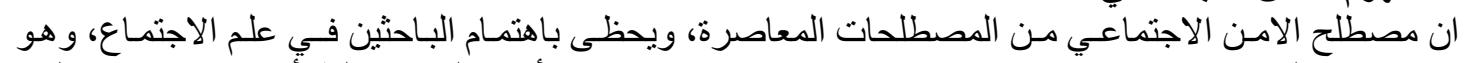

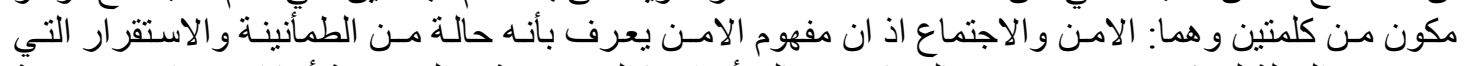

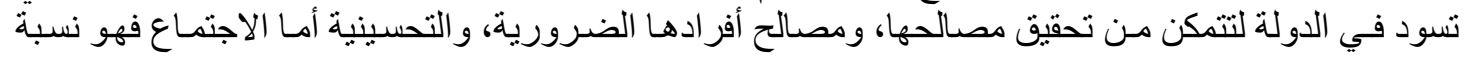




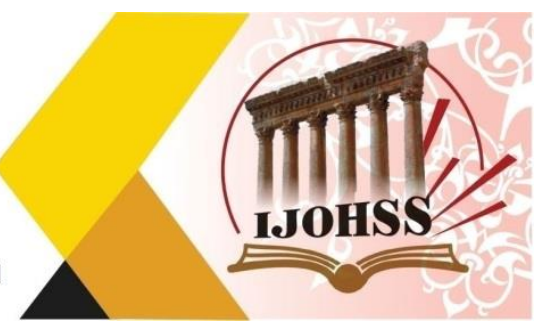

الكى الاجتماع؛ و هو وصف للسلوك أو الموقف نحو الآخرين وهو يعني المو اقف ذات فيها التأثير المتبادل بين

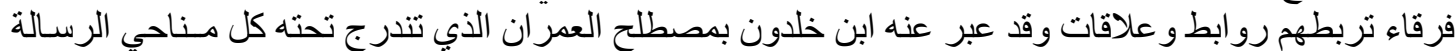
الانسانية ، وسائر أصناف الأمانة التي حملها الأنسان الأنسان (36).

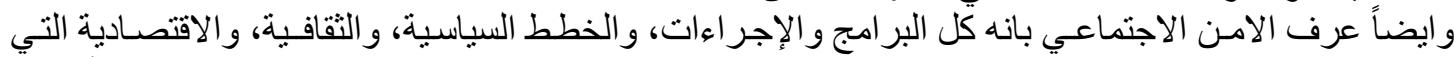

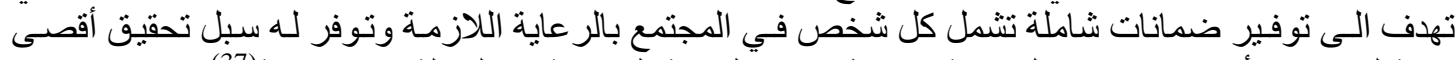

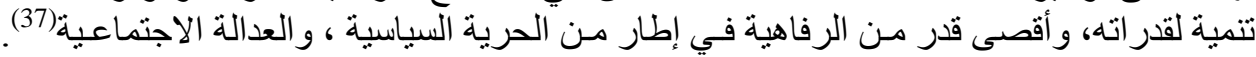

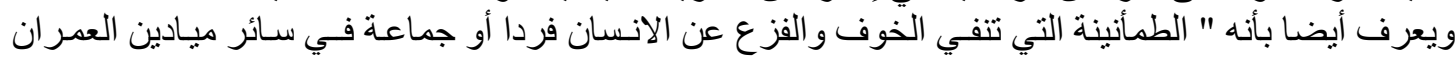

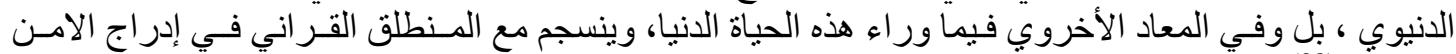

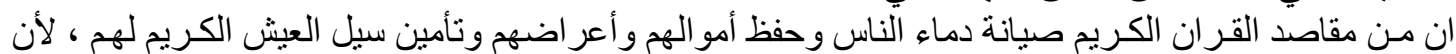

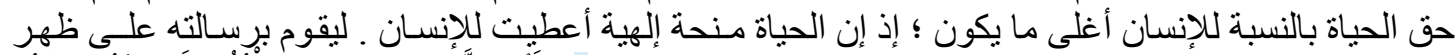

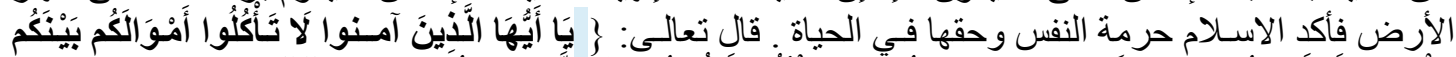

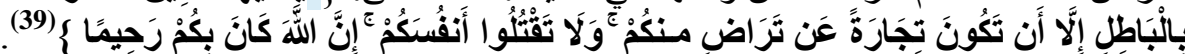

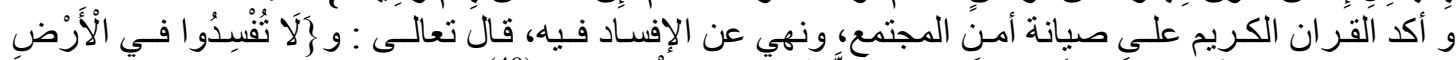

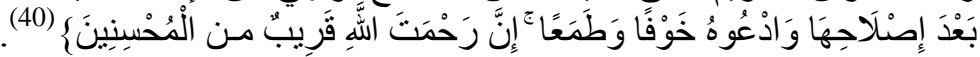

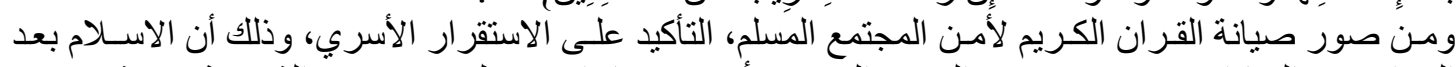

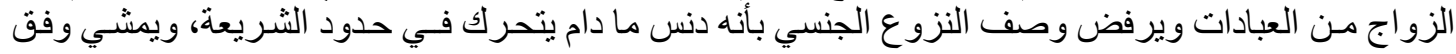

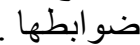

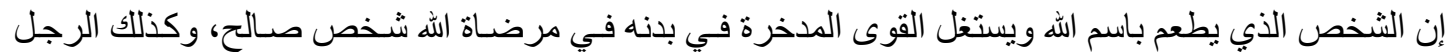

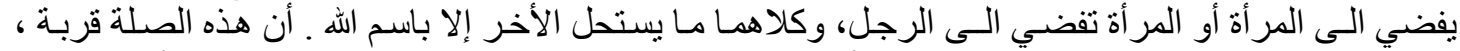

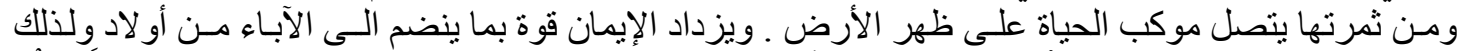

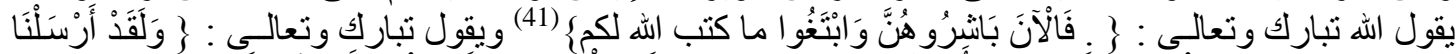

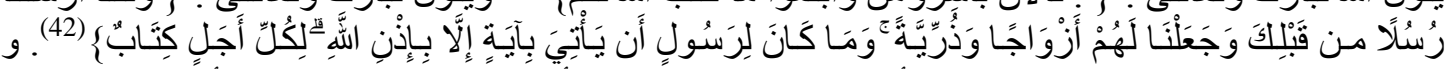

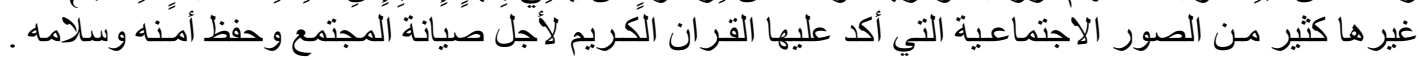

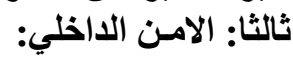

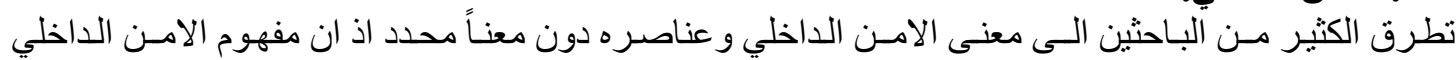

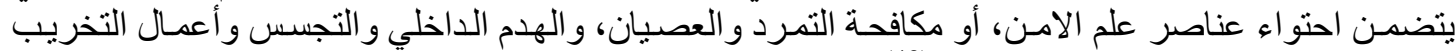

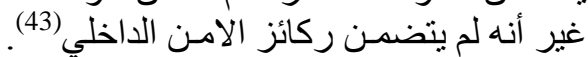

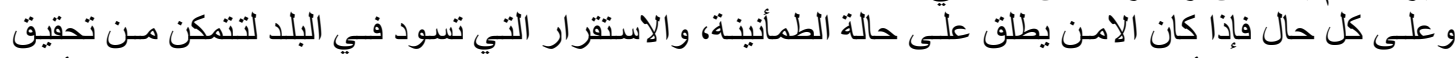

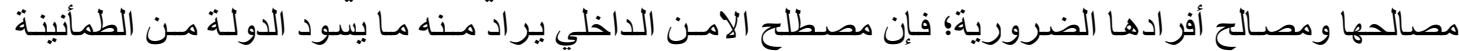

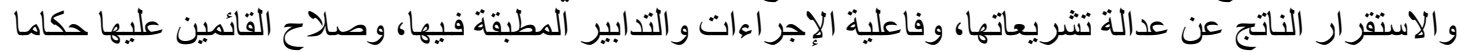

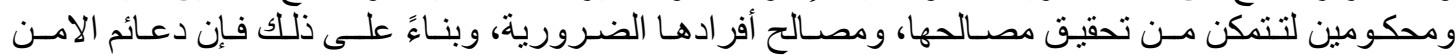

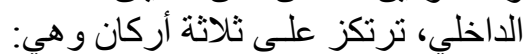

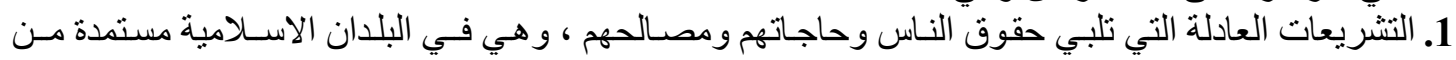
الوحي الإلهي المتصف بآلعدالة المالة المطلقة.

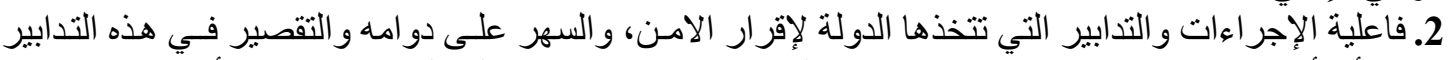

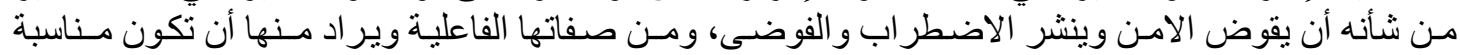

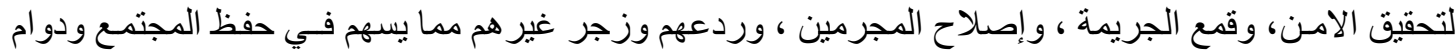

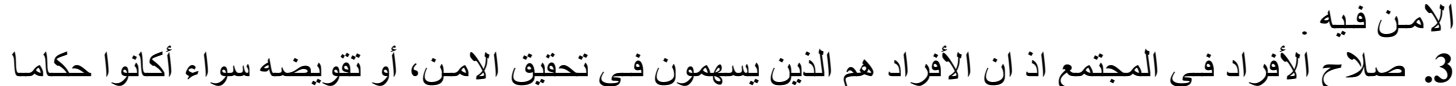
أم محكومين ، وصلاحهم مـن أهم العو امل التي تحملهم على لأنى تحقيق الامـن (44). 


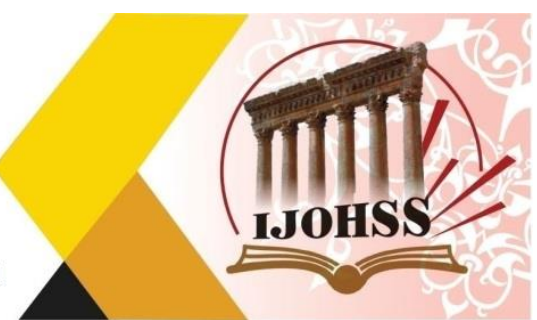

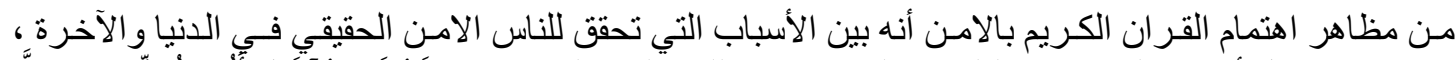

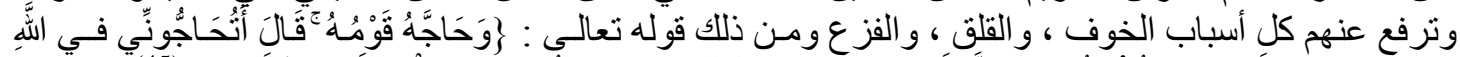

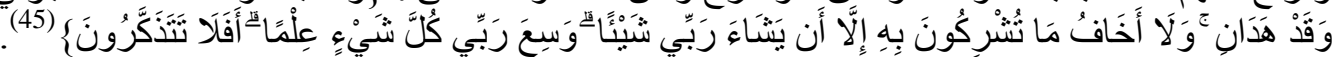

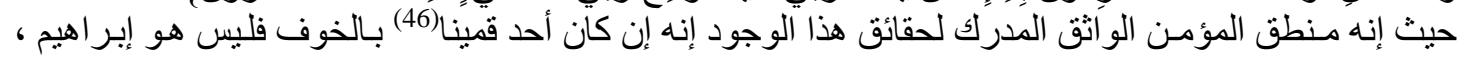

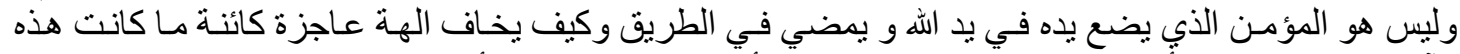

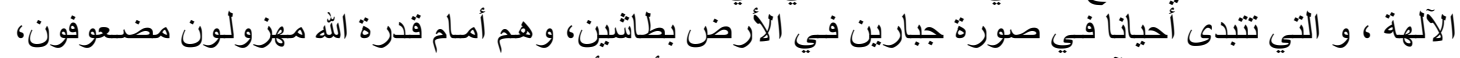

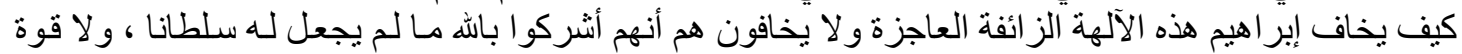

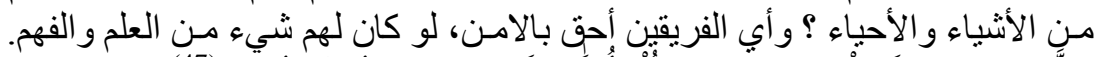

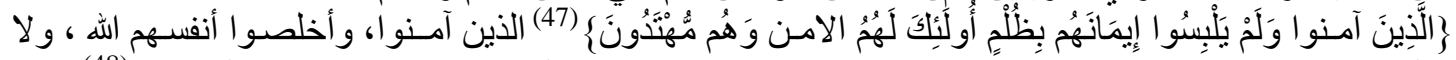

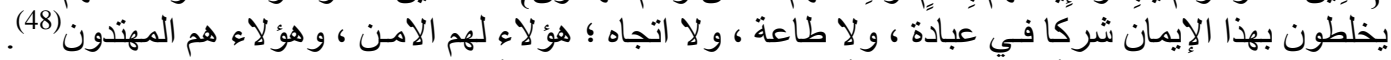

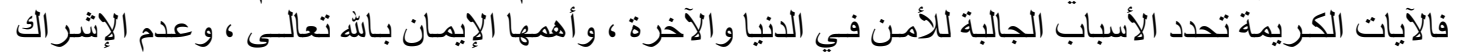

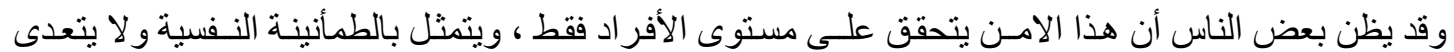

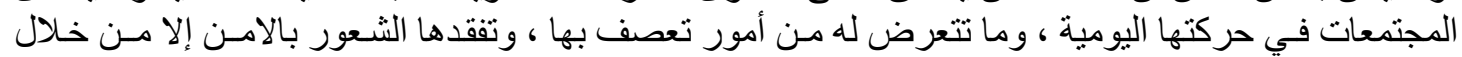

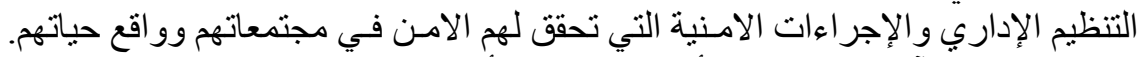

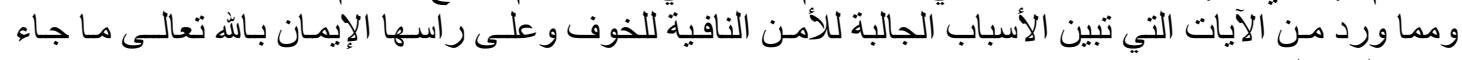

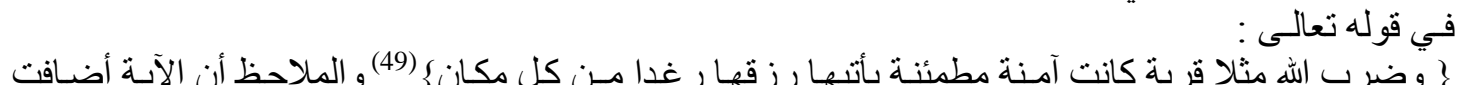

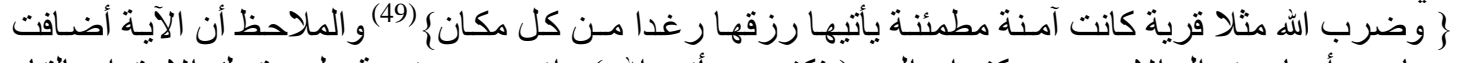

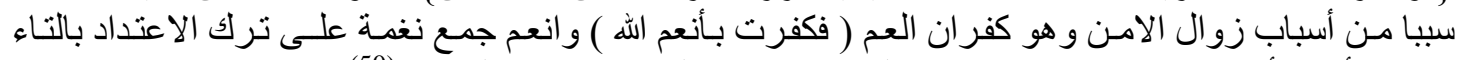

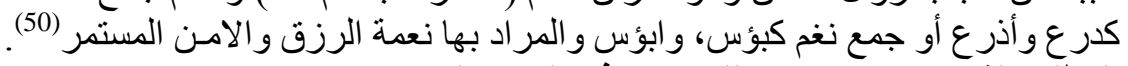

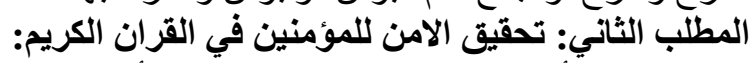

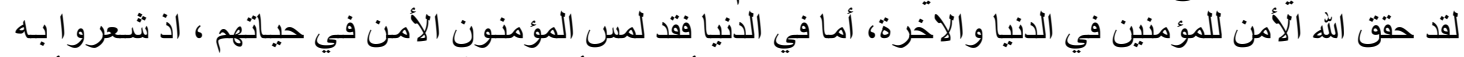

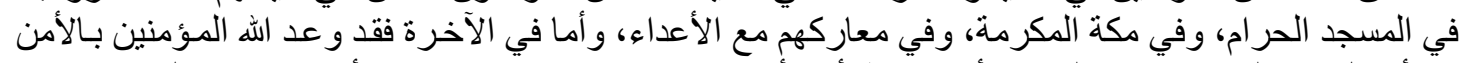

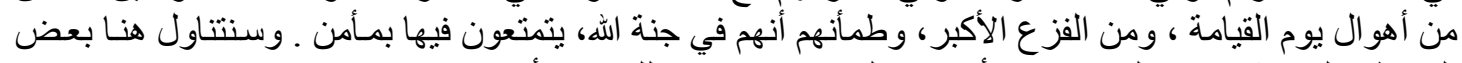

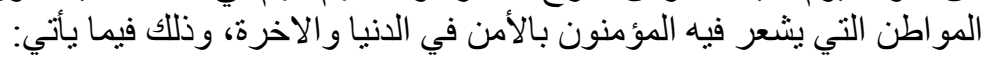

\section{أولا : تحقى الأمن للمؤمنين في الدنيا:}

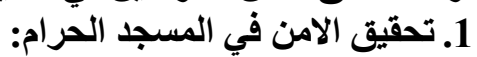

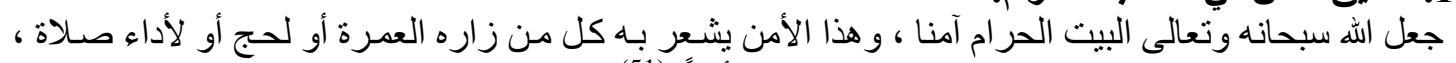

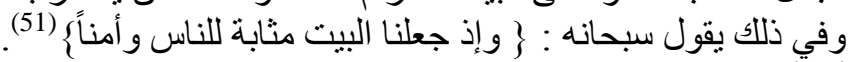

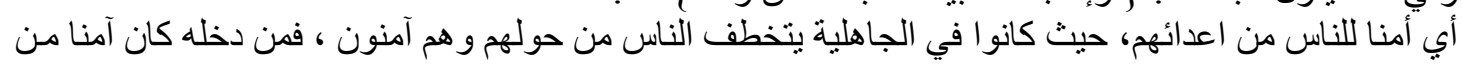

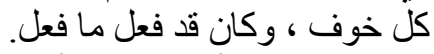

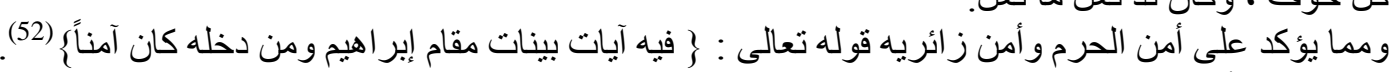

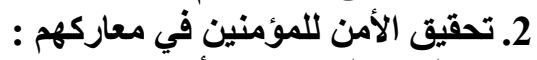

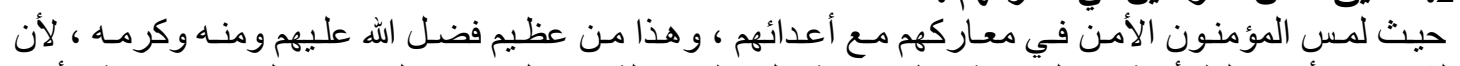

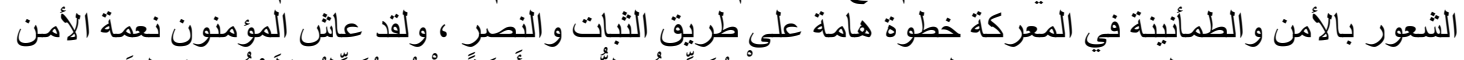

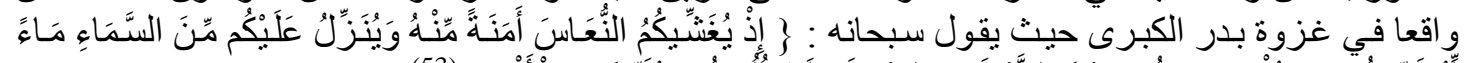

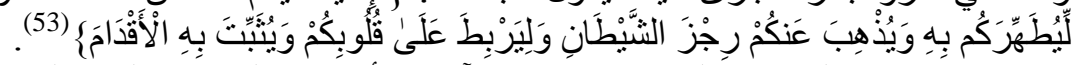

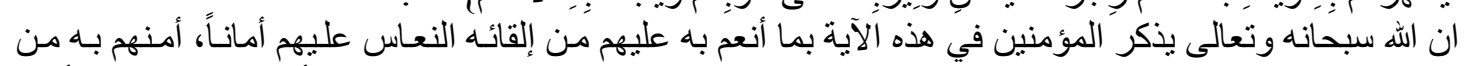

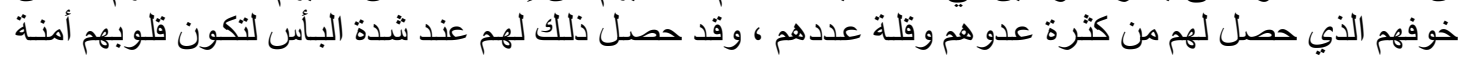
مطئنة بنصر الله ، وكان ذلك في معركة بدر الكبرى . 


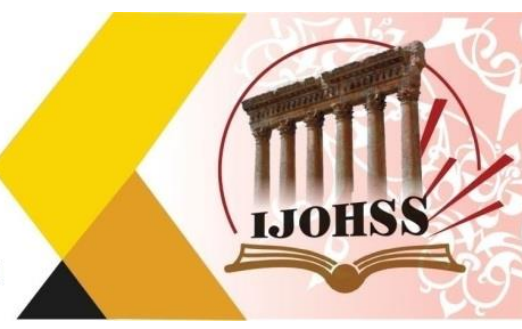

تانيا : تحقق الأمن للمؤمنين في الآخرة:

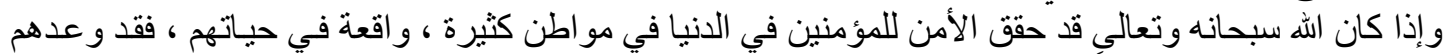

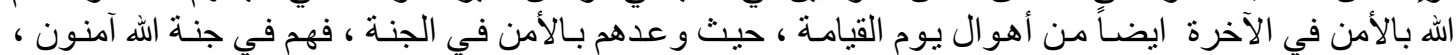

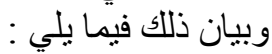

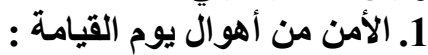

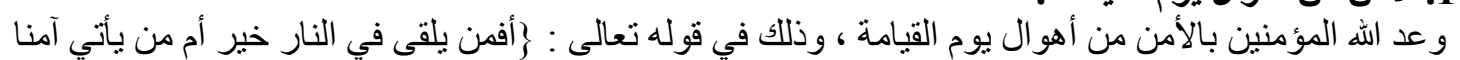

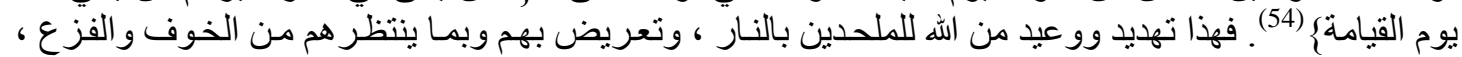

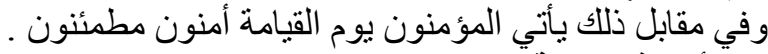

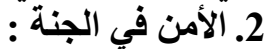

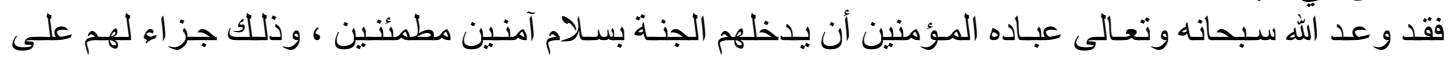

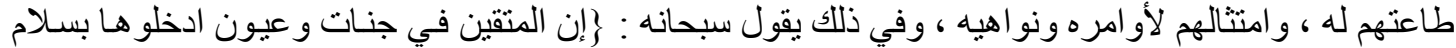

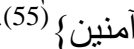

\section{المبحث الثاني \\ مظاهر الامسن في القران وأثره في حياة الناس}

$$
\text { وهـن هذه الأيات الامسن الداخلي في القـران الكريم: }
$$

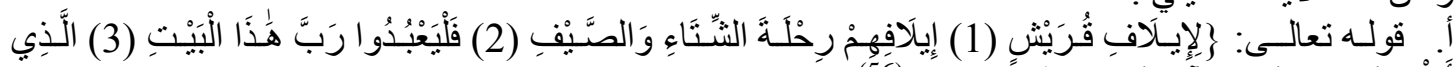

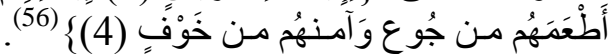

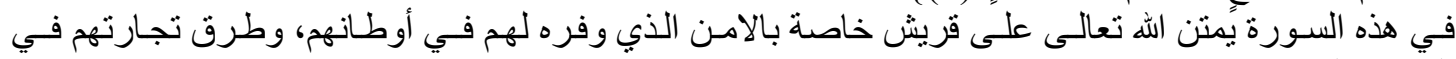

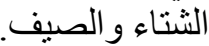

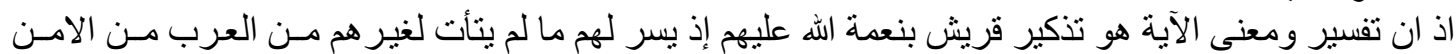

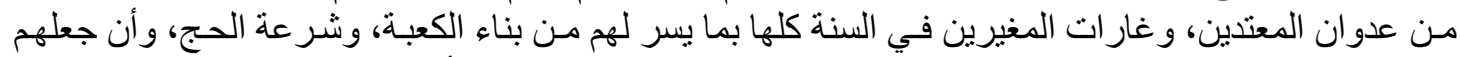

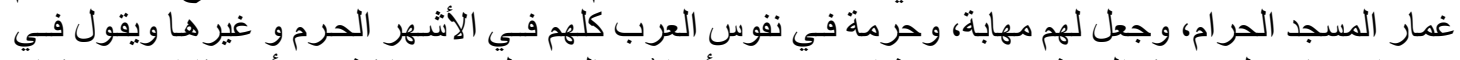

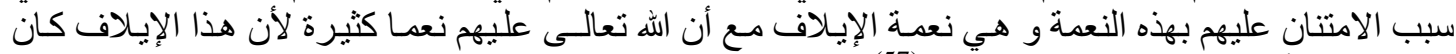
سببا جامعا لأهم النعم التي بها قو النم بقائهم (57).

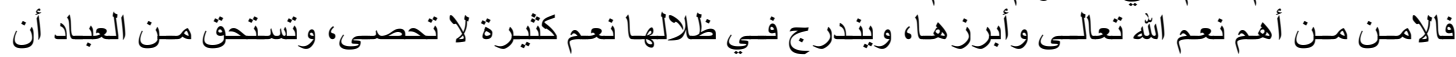
يشكروا الله تعالى عليها.

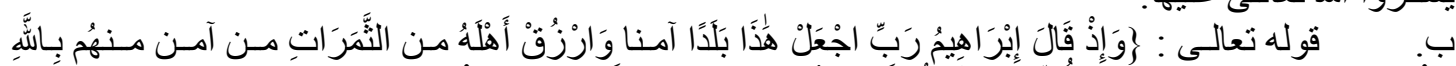

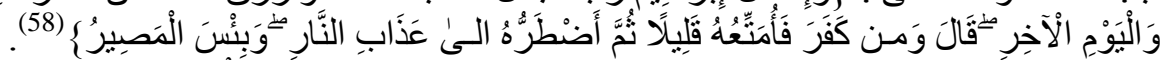

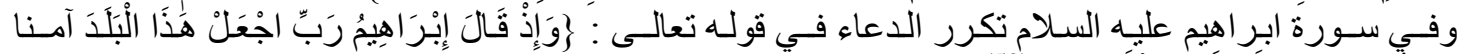

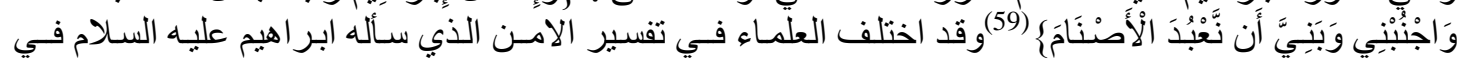

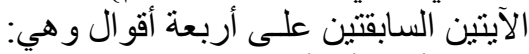

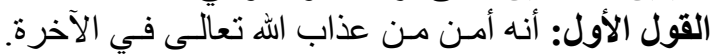

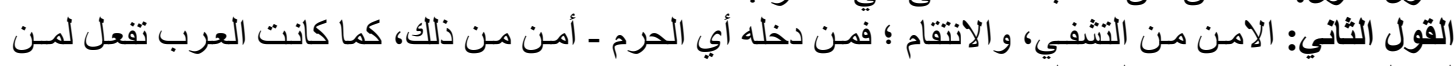

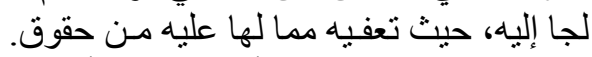

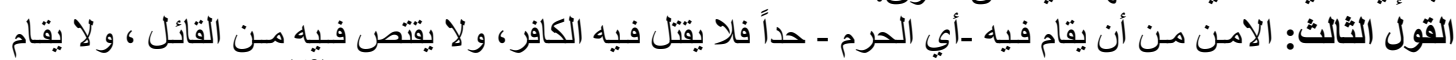

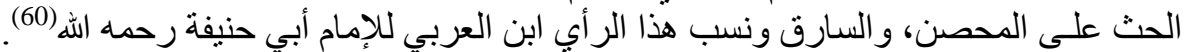

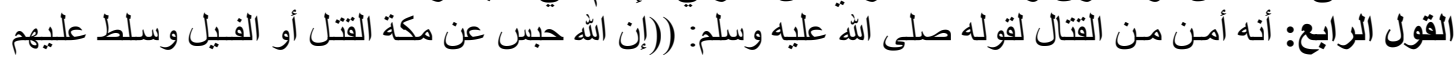

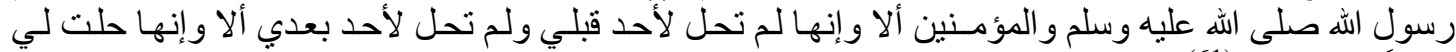

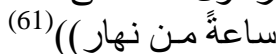




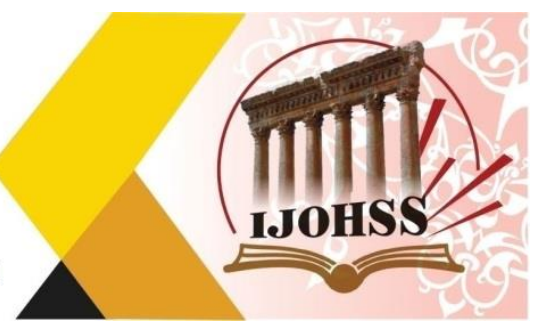

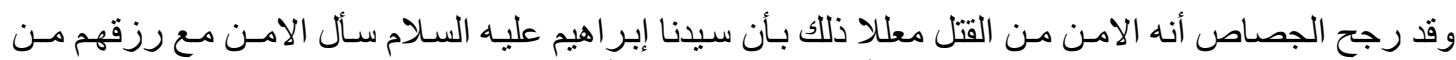

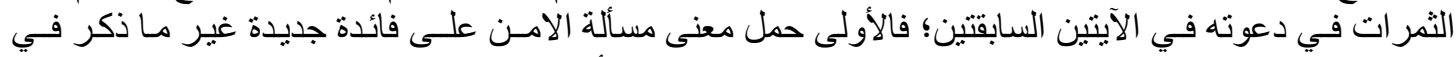

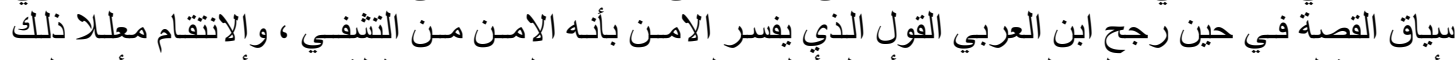

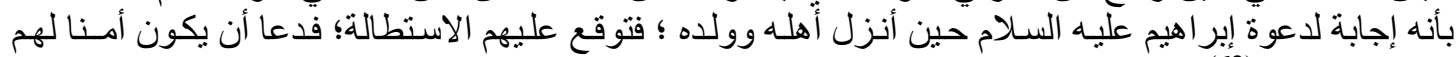

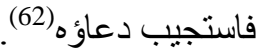

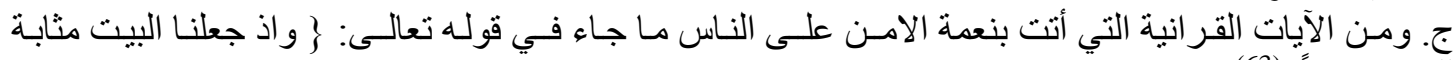

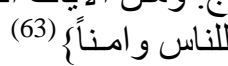

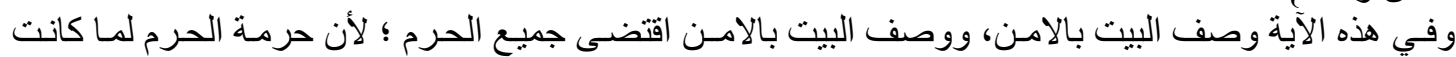

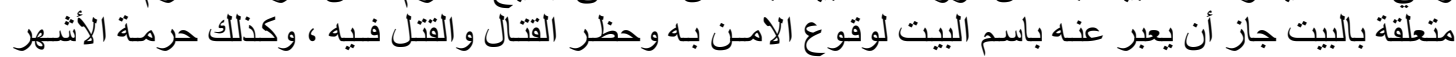

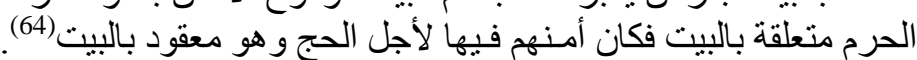

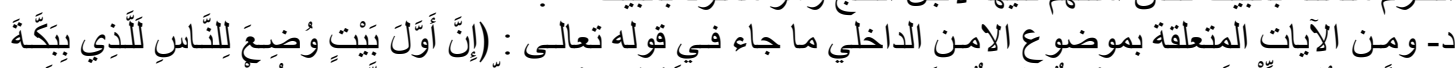

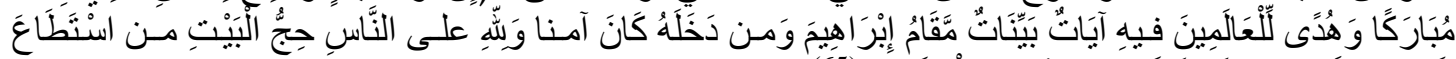

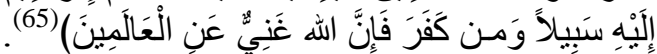

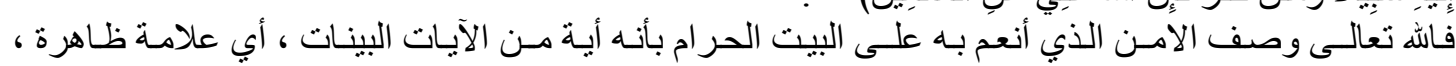

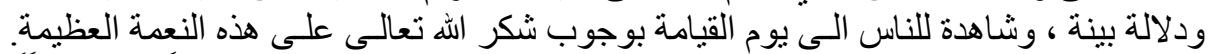

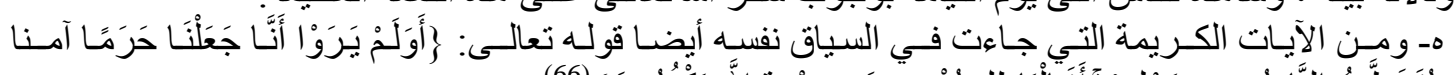

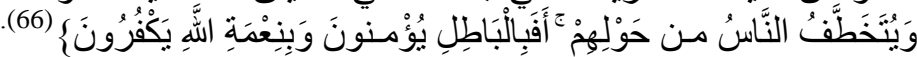

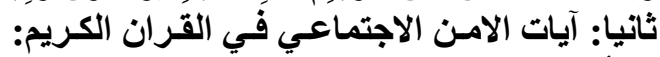

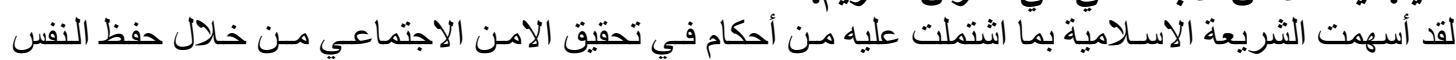

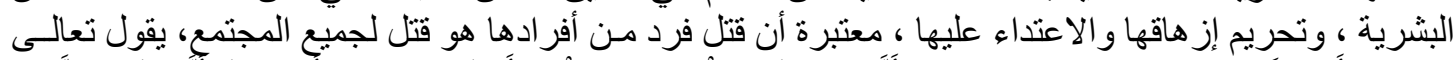

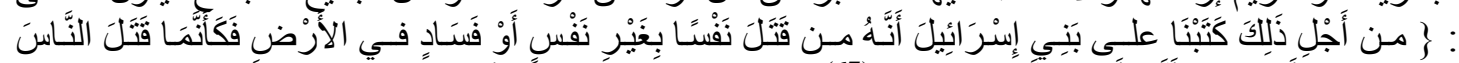

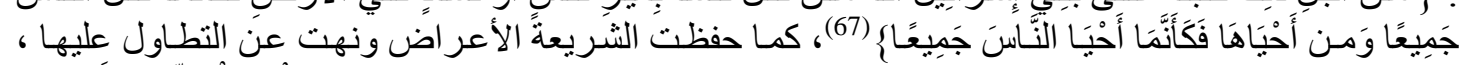

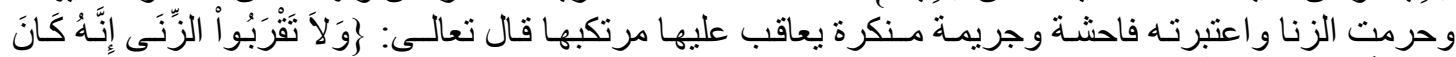

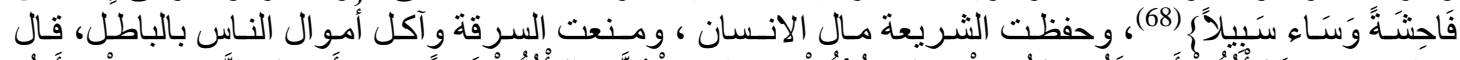

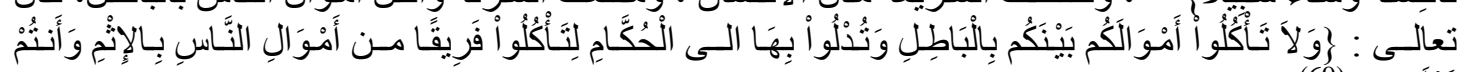
تَعْلَمُونَ)

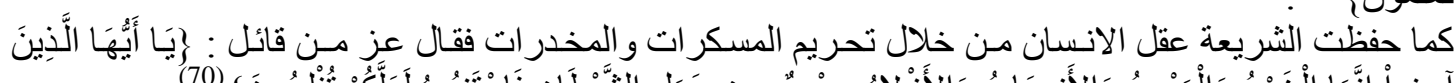

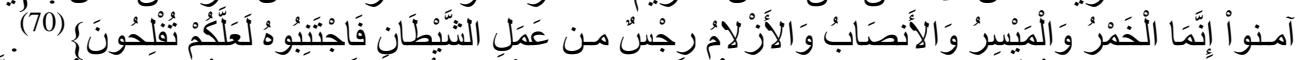

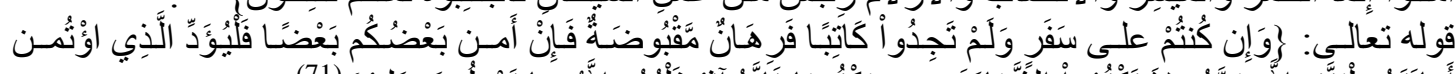

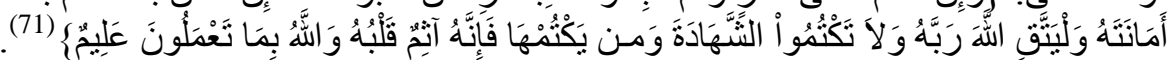

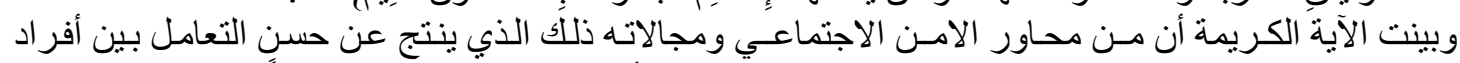

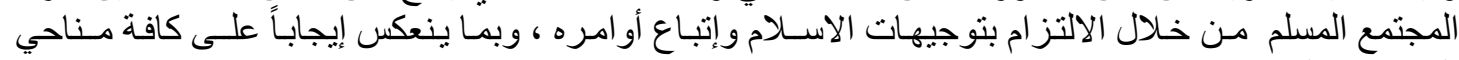

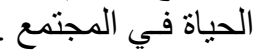

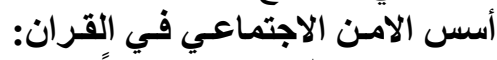

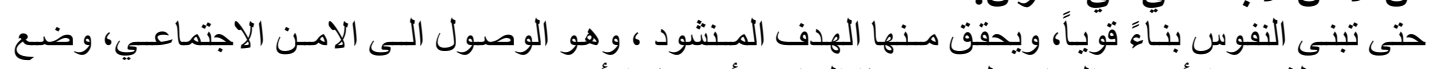

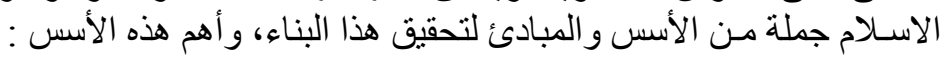

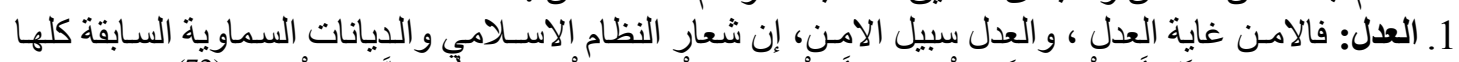

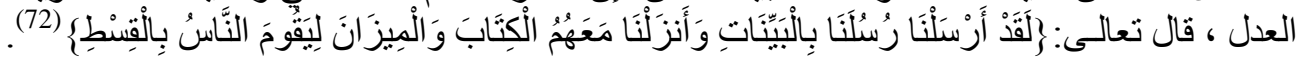

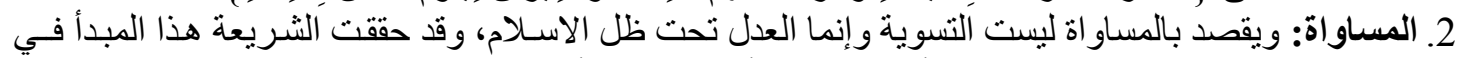

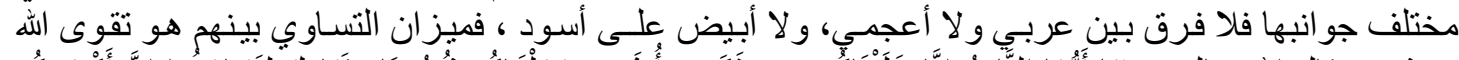

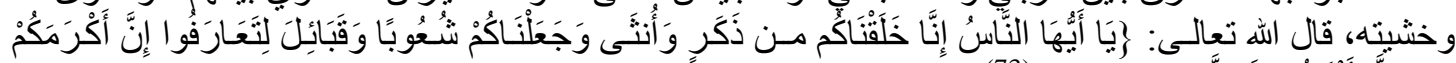

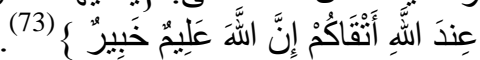




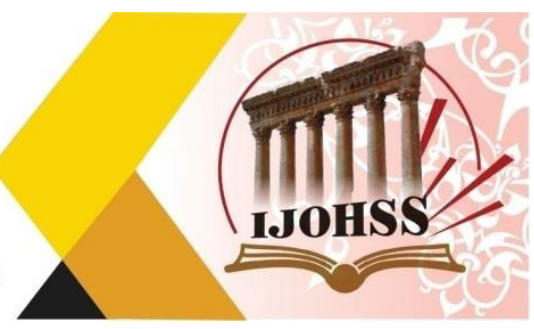

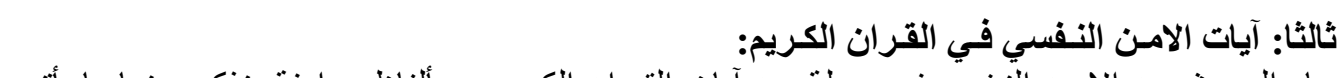

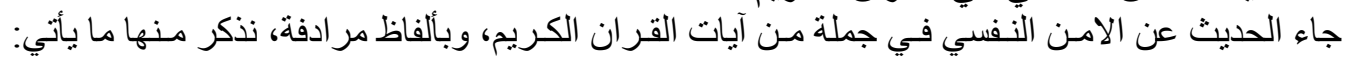

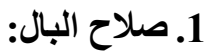

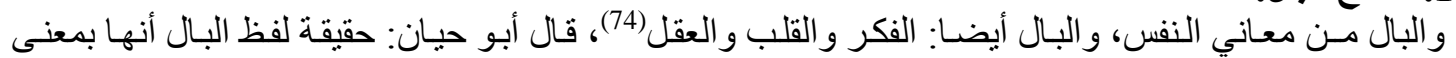

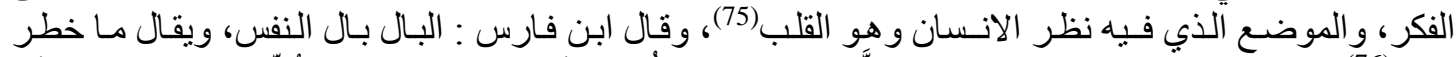

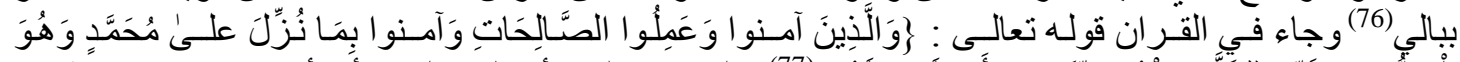

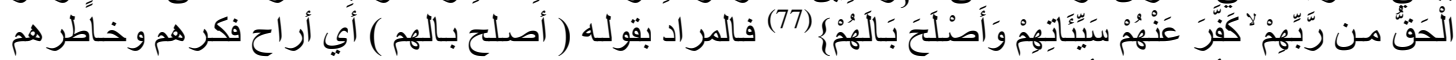
وجعل قلوبهم في أمسن وطمأنينة.

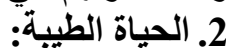

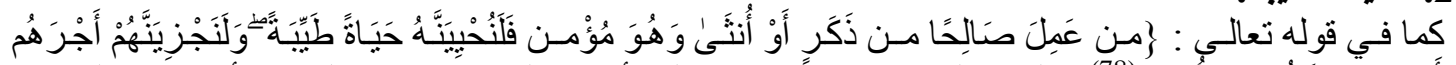

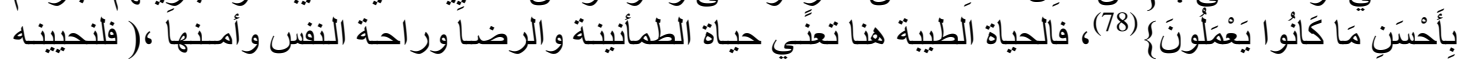

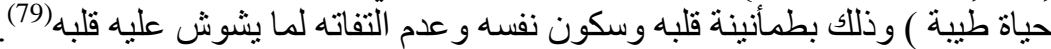
3. 3. السكينة :

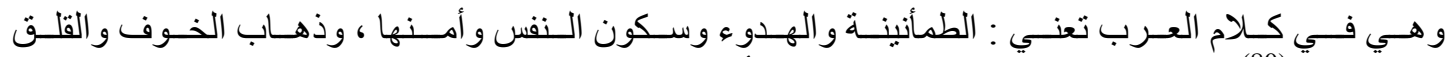

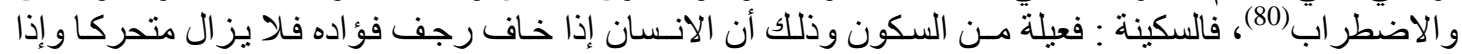

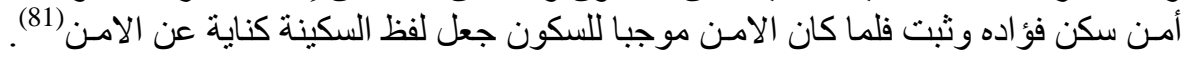

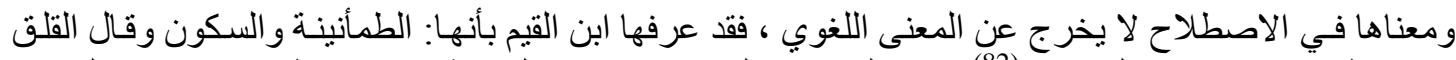

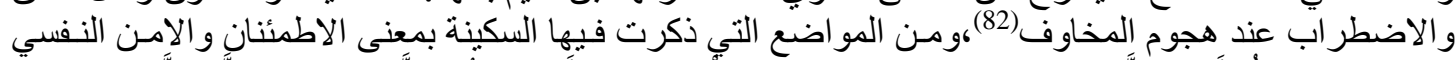

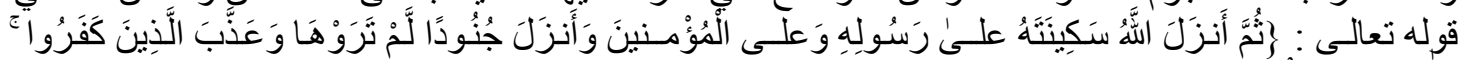

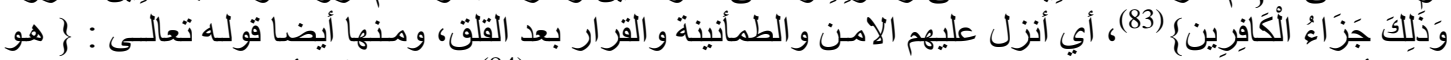

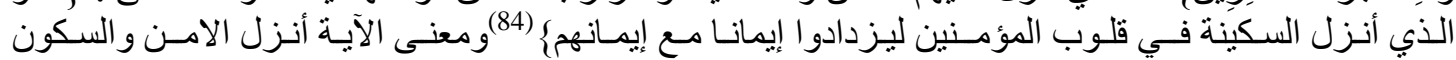

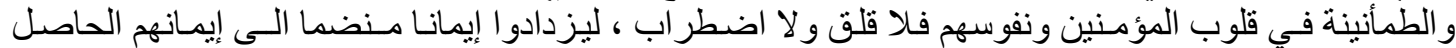
لهو مـن قبل (85).

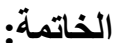

وفي ختام هذه الدراسة التي تتاولت الامـن في القران الكريم و أثره على حياة الناس بدر اسة بيانية، يمكن أن

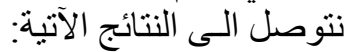

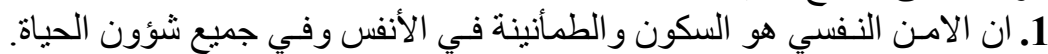

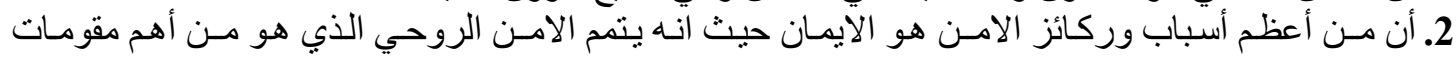

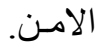

3. ان الامن فريضة شر عية وضرورة حياتية، و عدم توفره يوقف كل خطط التنمية.

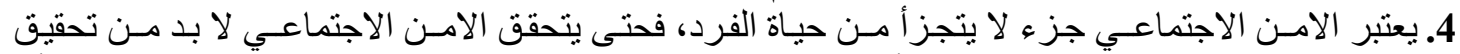

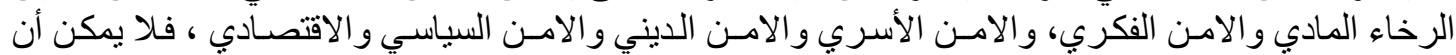

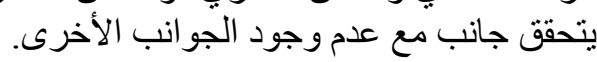

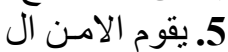
6. يقوم الامـن الداخلي على جلى جملة مـن المباديء والأسـس أهمها العدل و المسـاو اة و الحريـة و القوة والحزم فـي

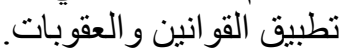

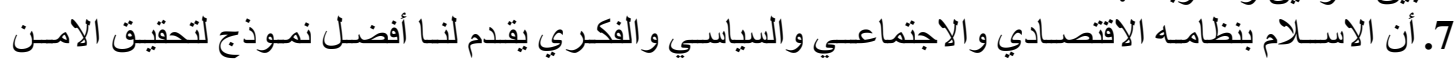

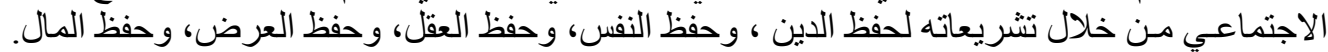

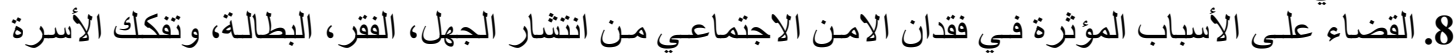
و إهمال الثباب ، ونحو هاء الانباب. 
() (1) سورة ال عمران: 154.

(2) مختار الصحاح، محمد بن ابي بكر الر ازي، مكتبة لبنان، بيروت، 1995، 11/1، مادة (أمن).

(3) تفسير الفخر الرازي، محمد بن ابي بكر الرازي، ط3، دار الفكر، بيروت، 1985، 32/16.

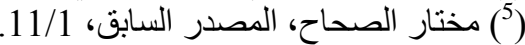

(6) لسان العرب، محمد بن مكرم ابن منظور ، دار صادر ، بيروت، 2000، ط1، 163/1.

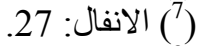

(9) معجم مفردات الفاظ القران، حسين بن محمد الاصفهاني، دار الكتب العلية، بيروت، ص90/13.

(9) (9) لسان العرب، المصدر السابق، 22/13.

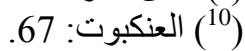

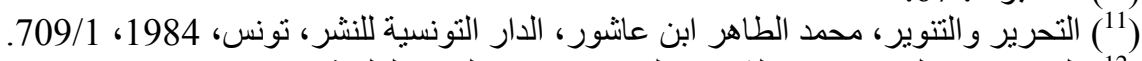

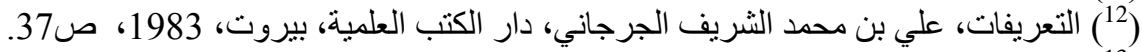

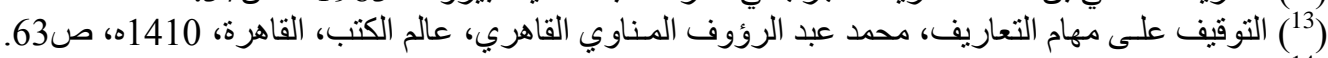

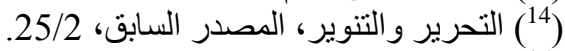

(15) مقومات الامـن في القران الكريم، ابر اهيم سليمان الهويمل، المجلة العربية للار اسـات الامـنية، الرياض، العدد29،

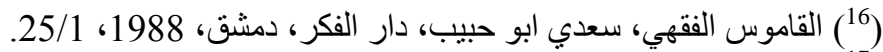

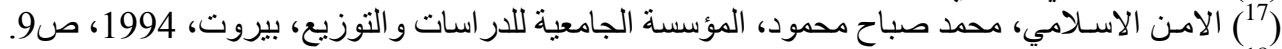

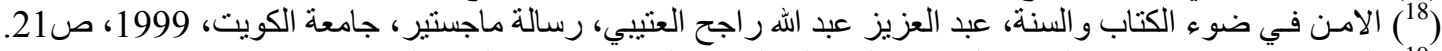

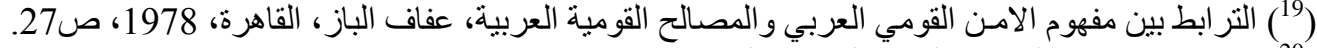

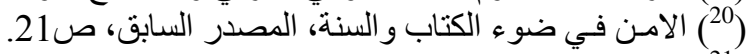

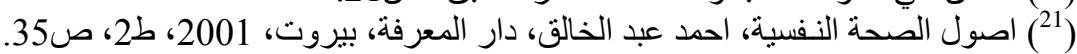

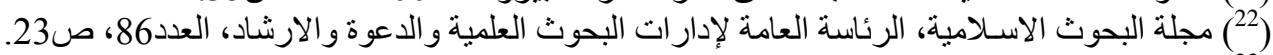

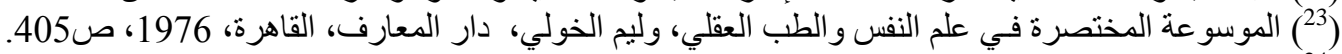

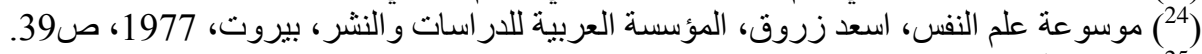

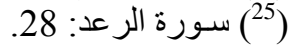

(26) جامع البيان في تأويل القران، محمد بن جرير يزيد بن كثير الآملي الطبري، مؤسسة الرسالة، 1420ه، ، 432/16. (27) (27) الانفال: 10.

4 (28) جامع البيان، المصدر السابق، 10/18/28.

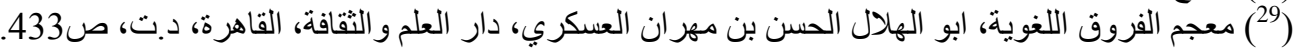

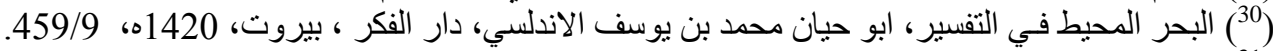

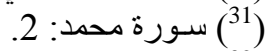

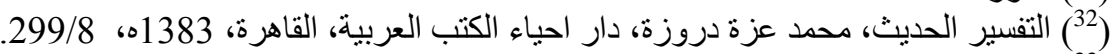

(33) نظم الدرر في تناسب الآيات والسور ، البر الهيم بن عمر بن حسن البقاعي، دار الكتب الاسـلامية، القاهرة، 1389/18. ( ) (35) تيسير الكريم الرحمـن في تفسير كلام المنان، عبد الرحمن بن ناصر بن عبد الله السعدي، مؤسسة الرسـالة، بيروت،

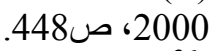

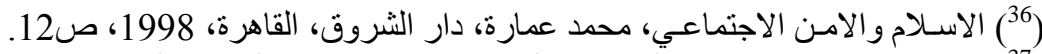

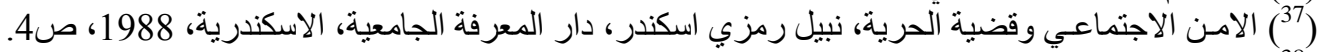

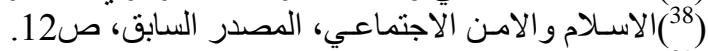

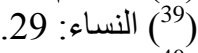
( الاعر اف: 56.

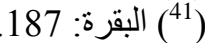

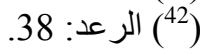




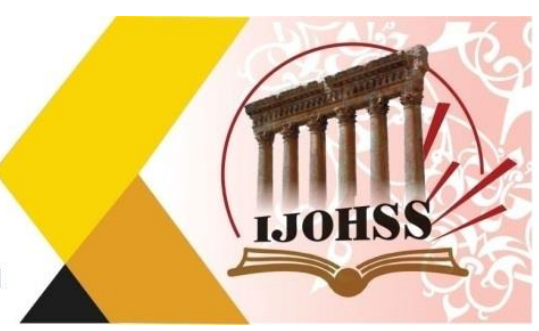

(33) در اسـة فـي الامـن الخـارجي العر اقي واستر اتيجية تحقيقه، ثنامر كامل محمد، مسنشور ات وزارة الثقافة و الاعـلام،

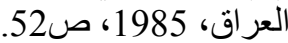

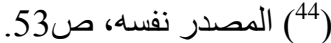
( ) ( الانعام: 80. (46) (47) مختار الصحاح، المصدر السابق، ص230. ( الانعام: 82. (48) في ظلال القران، سيد قطب، دار الثروق، بيروت، 1980، 1142/2.

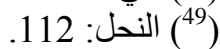
(50) تفسير ابو السعود، القاضي ابو السعود محمد بن محمد الحنفي، دار الكتب العلمية، بيروت، 97/4.

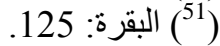
. (ال) .11: (11)

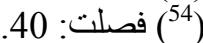

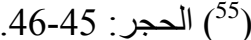

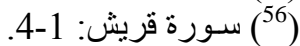

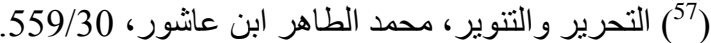

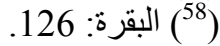

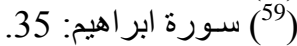

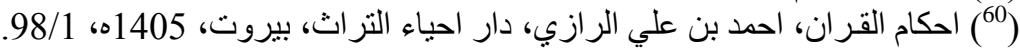

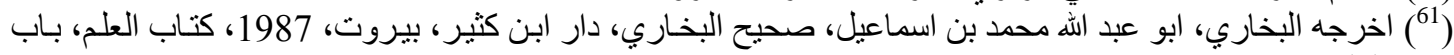

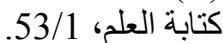
(62) احكام القران، المصدر السابق، 53/1. (63)

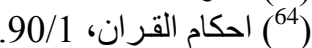
(ال عمران: (67)

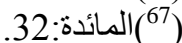

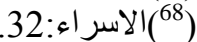

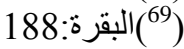

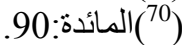

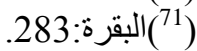
( ) الحديد: 25.

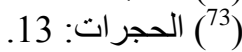
(74) (74) مختار الصحاح، ص427. (5) (759/9 البحر المحيط، 321/1. (77) .97: النحئ.

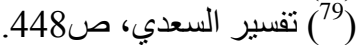
(80)

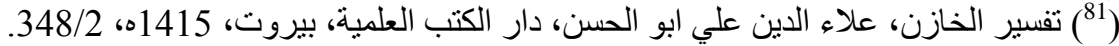
(1992) ددارج السالكين بين منازل ايالك نعبد واياك نستعين، محمد بن ابي بكر ابن قيم الجوزية، دار الكتاب العربي، بيروت، .482/2، 1996

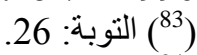
(الفتح: 4.84

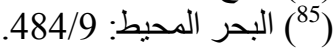




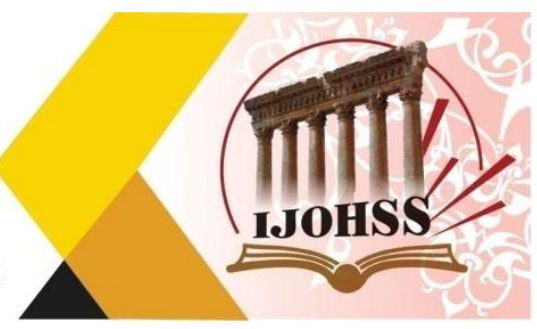

المصادر

القران الكريم

1.احكام القران، احمد بن علي الرازي، دار احياء التراث، بيروت، 1405ه، الإن.

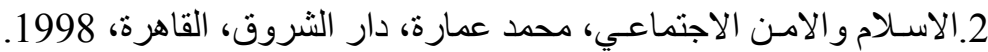

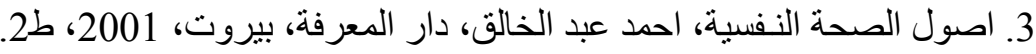

4.الامـن الاجتماعي وقضية الحرية، نبيل رمزي اسكندر ، دار المعرفة الجامعية، الاسكندرية، 1988.

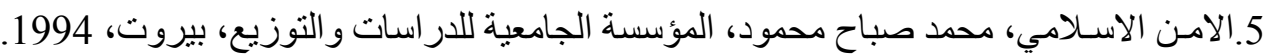

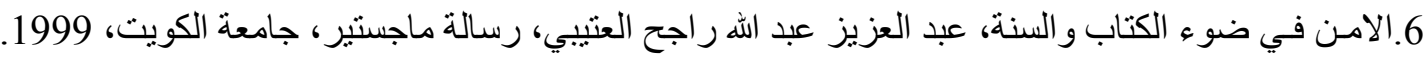

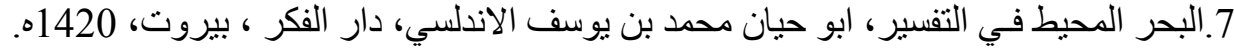

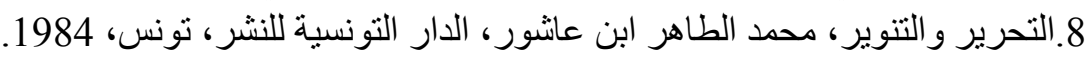

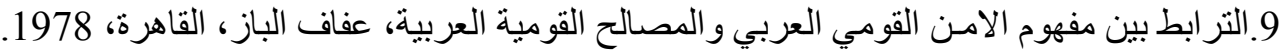

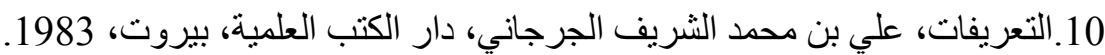

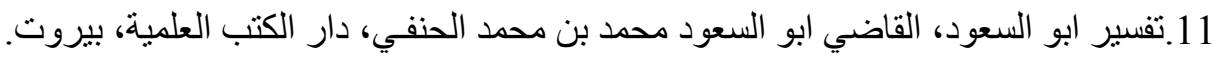

12.التفسير الحديث، محمد عزة دروزة، دار احياء الكتب العربية، القاهرة، 1383ه 138ه.

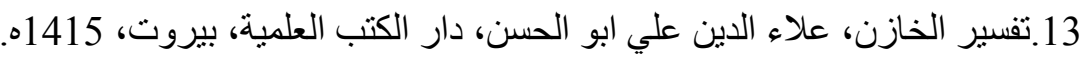

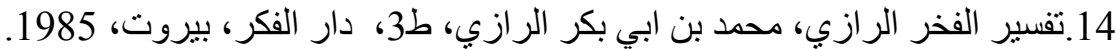

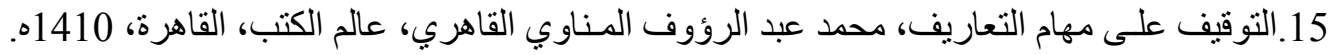

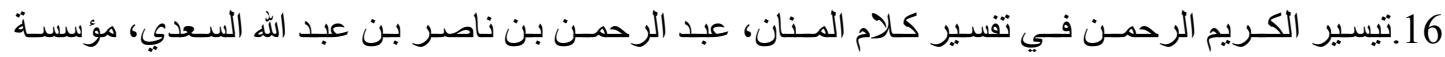

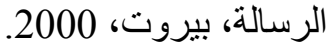

17.جامع البيان في تأويل القران، محمد بن جرير يزيد بن كثير الآملي الطبري، مؤسسة الرسالة، 1420هـ

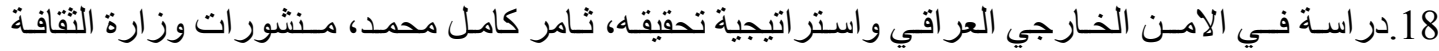

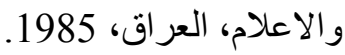

19.صحيح البخاري، ابو عبد الله محمد بن اسماعيل، ، دار ابن كثير ، بيروت، 1987.

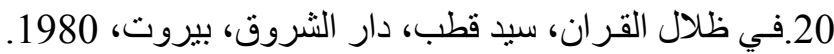

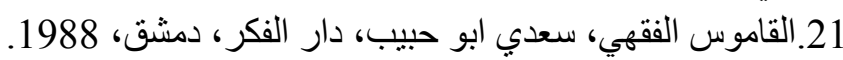

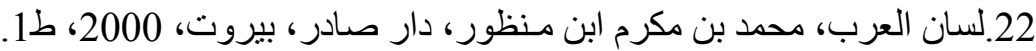

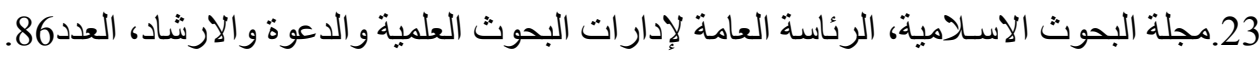

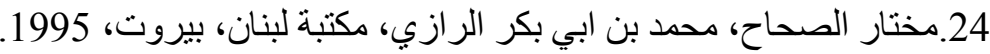

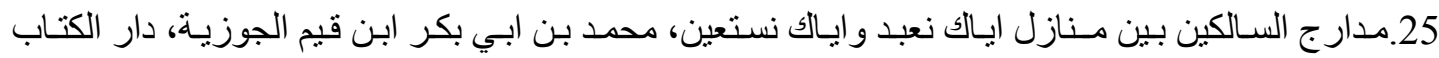

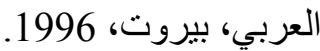

26.معجم الفروق اللغوية، ابو الهلال الحسن بن مهران العسكري، دار العلم والثقافة، القاهرة، د.ت.

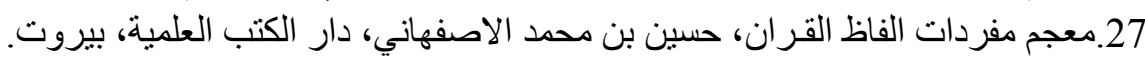

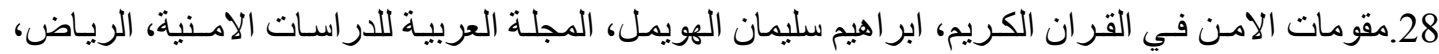

العدد28. (29.

29.الموسوعة المختصرة في علم النفس والطب العقلي، وليم الخولي، دار المعارف، القاهرة، 1976. 30.موسو عة علم النفس، اسعد زروق، المؤسسة العربية للار اسات و النشر ، بيروت، الني، 1977. 


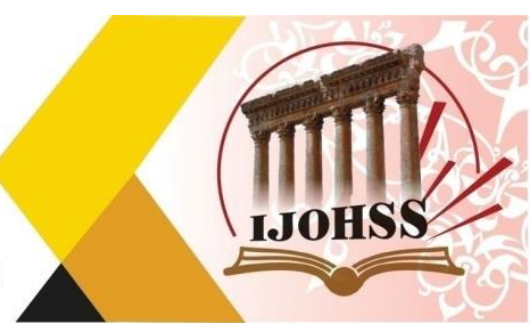

31.نظم الدرر في تناسب الآيات والسور، ابر اهيم بن عمر بن حسن البقاعي، دار الكتب الاسـلامية، القاهرة.

\section{References}

- The Holy Qur'an

1. Provisions of the Qur'an, Ahmed bin Ali Al-Razi, Dar Revival of Heritage, Beirut, $1405 \mathrm{AH}$.

2. Islam and Social Security, Muhammad Emara, Dar Al-Shorouk, Cairo, 1998.

3. The Fundamentals of Mental Health, Ahmed Abdel-Khaleq, Dar Al-Marefa, Beirut, 2001, 2nd Edition.

4. Social Security and the Cause of Freedom, Nabil Ramzy Iskandar, University Knowledge House, Alexandria, 1988.

5. Islamic Security, Muhammad Sabah Mahmoud, University Foundation for Studies and Distribution, Beirut, 1994.

6. Security in the Light of the Qur'an and Sunnah, Abdul Aziz Abdullah Rajeh AlOtaibi, MA thesis, Kuwait University, 1999.

7. The Ocean in Interpretation, Abu Hayyan Muhammad bin Yusuf Al-Andalusi, Dar Al-Fikr, Beirut, $1420 \mathrm{AH}$.

8. Liberation and Enlightenment, Muhammad Al-Taher Ibn Ashour, Tunisian Publishing House, Tunis, 1984.

9. The Interrelationship between the Concept of Arab National Security and Arab National Interests, Afaf El-Baz, Cairo, 1978.

10. Definitions, Ali bin Muhammad al-Sharif al-Jurjani, Dar al-Kutub al-Ilmiyya, Beirut, 1983.

11. Tafsir Abu Al-Saud, Judge Abu Al-Saud Muhammad Bin Muhammad Al-Hanafi, Dar Al-Kutub Al-Ilmiyya, Beirut.

12. Modern Interpretation, Muhammad Azza Darwaza, House of Reviving Arabic Books, Cairo, $1383 \mathrm{AH}$.

13. Tafsir al-Khazen, Alaa al-Din Ali Abu al-Hasan, Dar al-Kutub al-Ilmiyya, Beirut, $1415 \mathrm{AH}$.

14. Interpretation of Al-Fakhr Al-Razi, Muhammad bin Abi Bakr Al-Razi, 3rd Edition, Dar Al-Fikr, Beirut, 1985.

15. Detention on Definitions Tasks, Muhammad Abd al-Raouf al-Manawi al-Qaheri, World of Books, Cairo, $1410 \mathrm{AH}$.

16. Tayseer Al-Karim Al-Rahman in the Interpretation of the Words of Al-Mannan, Abdul Rahman bin Nasser bin Abdullah Al-Saadi, Al-Resala Foundation, Beirut, 2000 .

17. Jami' al-Bayan fi Ta'wil al-Qur'an, Muhammad ibn Jarir Yazid ibn Kathir alAmali al-Tabari, al-Risala Foundation, $1420 \mathrm{AH}$.

18. A study of the Iraqi external security and its realization strategy, Thamer Kamel Muhammad, Publications of the Ministry of Culture and Information, Iraq, 1985.

19. Sahih Al-Bukhari, Abu Abdullah Muhammad bin Ismail, Dar Ibn Kathir, Beirut, 1987. 


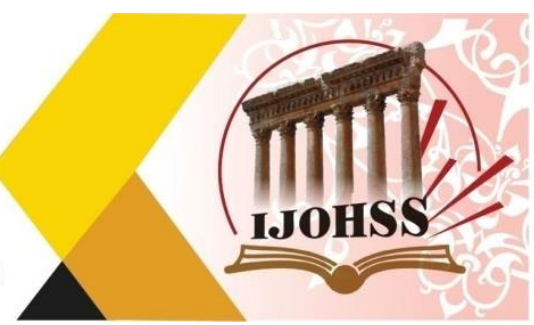

20. In the Shadows of the Qur'an, Sayed Qutb, Dar Al-Shorouk, Beirut, 1980.

21. Fiqh Dictionary, Saadi Abu Habib, Dar Al-Fikr, Damascus, 1988.

22. Lisan al-Arab, Muhammad bin Makram Ibn Manzur, Dar Sader, Beirut, 2000, 1st ed.

23. Journal of Islamic Research, General Presidency of the Departments of Scientific Research, Call and Guidance, No. 86.

24. Mukhtar Al-Sahah, Muhammad bin Abi Bakr Al-Razi, Library of Lebanon, Beirut, 1995.

25. Runways of those who walk between the homes of "You do not worship, and You do not seek help," Muhammad ibn Abi Bakr ibn Qayyim al-Jawziyya, Dar alKitab al-Arabi, Beirut, 1996.

26. A Dictionary of Linguistic Differences, Abu al-Hilal al-Hasan bin Mahran alAskari, House of Science and Culture, Cairo, d.

27. A Dictionary of the Vocabulary of the Qur'an, Hussein bin Muhammad AlIsfahani, Dar Al-Kutub Al-Ilmiyya, Beirut.

28. The Elements of Security in the Noble Qur'an, Ibrahim Suleiman Al-Huwaimel, The Arab Journal for Security Studies, Riyadh, No. 29.

29. The Concise Encyclopedia of Psychology and Mental Medicine, William AlKhouli, Dar Al-Maaref, Cairo, 1976.

30. Encyclopedia of Psychology, Asaad Zarrouk, The Arab Foundation for Studies and Publishing, Beirut, 1977.

31. Al-Durar systems in proportion to verses and surahs, Ibrahim bin Omar bin Hassan Al-Beqai, Islamic Book House, Cairo. 